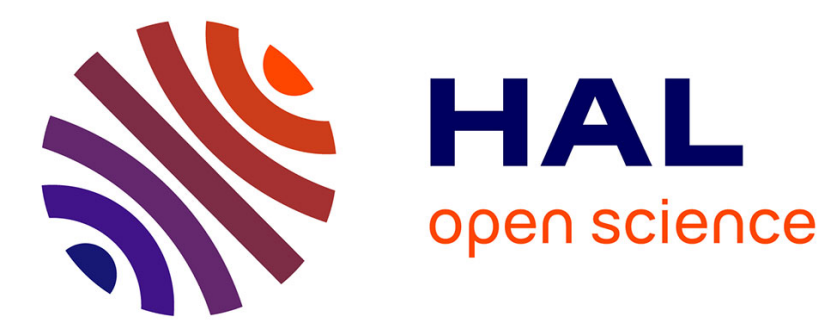

\title{
A Critical Review of the Database Acquired for the Long-Term Surveillance of the Middle Atmosphere by the French Rayleigh Lidars
}

Philippe Keckhut, Alain Hauchecorne, Marie-Lise Chanin

\section{- To cite this version:}

Philippe Keckhut, Alain Hauchecorne, Marie-Lise Chanin. A Critical Review of the Database Acquired for the Long-Term Surveillance of the Middle Atmosphere by the French Rayleigh Lidars. Journal of Atmospheric and Oceanic Technology, 1993, 10 (6), pp.850-867. 10.1175/15200426(1993)0102.0.CO;2 . hal-03124603

\section{HAL Id: hal-03124603 \\ https://hal.science/hal-03124603}

Submitted on 28 Jan 2021

HAL is a multi-disciplinary open access archive for the deposit and dissemination of scientific research documents, whether they are published or not. The documents may come from teaching and research institutions in France or abroad, or from public or private research centers.
L'archive ouverte pluridisciplinaire HAL, est destinée au dépôt et à la diffusion de documents scientifiques de niveau recherche, publiés ou non, émanant des établissements d'enseignement et de recherche français ou étrangers, des laboratoires publics ou privés. 


\title{
A Critical Review of the Database Acquired for the Long-Term Surveillance of the Middle Atmosphere by the French Ragleigh Lidars
}

\author{
P. Keckhut, A. Hauchecorne, and M. L. Chanin \\ Service d'Aéronomie du CNRS, Verrieres le Buisson, France
}

(Manuscript received 19 October 1992, in final form 19 April 1993)

\begin{abstract}
The database obtained by Rayleigh lidars over the south of France is now used for monitoring the middleatmosphere structure and to validate satellite data. For these reasons it is crucial to ensure the quality of the data. The purpose of this paper is to review all possible sources of errors that could induce random or systematic bias in the temperature measurements. The characteristics of the lidars, the procedures used, as well as the data reduction software are then reviewed. Comparisons made between the lidar and other available techniques and between lidars of different characteristics lead to the conclusion that an accuracy of $\mathbb{K} \mathrm{K}$ can be attained between 30 and about $70 \mathrm{~km}$ depending on the lidar power. The method itself is not affected by drift with time and provides absolute temperature data without any need of calibration and therefore is one of the best instruments for long-term monitoring.
\end{abstract}

\section{Introduction}

Vertical soundings of the atmosphere by Rayleigh lidar make it possible to determine an absolute measurement of middle stratosphere $(30 \mathrm{~km})$ and upper mesosphere $(80-90 \mathrm{~km})$ temperatures. The high precision of these measurements, the ease of implementation, and the possibility of adapting the integration period and vertical resolution to the temporal and spatial variations of the atmosphere, have resulted in the study of a wide range of geophysical phenomena including: gravity waves (Wilson et al. 1990, 1991a,b), tides (Gille et al. 1991), stratospheric warmings and planetary waves (Hauchecorne and Chanin 1982, 1983), mesospheric inversions (Hauchecorne et al. 1987), the oscillation of the 27-day solar cycle (Keckhut and Chanin 1992), climatology (Chanin et al. 1985,1990 ), the influence of the 11-year solar cycle (Chanin et al. 1987; Keckhut and Chanin 1989), and long-term trends of anthropogenic origin (Hauchecorne et al. 1991).

Due to the precision of the measurements taken with this instrument (no drift or adjustment) they are often used as references when comparing other measuring techniques (Finger et al. 1993). The possibility of obtaining long-term trends, in spite of the short-term variance in the temperature, is directly related to the duration and precision of the database, as well as to

Corresponding author address: Dr. P. Keckhut, Centre National de la Recherche Scientifique, Service D'Aeronomie, BP N 3, Verrieres le Buisson, France, 91371. our knowledge of the natural variations in the atmosphere. As the stratosphere is expected to cool down approximately by $1 \mathrm{~K}$ per decade under the combined influence of $\mathrm{O}_{3}$ depletion and $\mathrm{CO}_{2}$ increase, the absolute precision of these measurements is a fundamental parameter. The measuring instrument must be sensitive enough to discern such variation, and also be able to guarantee precision throughout the entire period. All possible sources of error (random and systematic), and their evolution in time must therefore be identified.

Until now, observations of temperature variations in the middle atmosphere were carried out by rocketsonde, by the study of falling spheres, and most recently by satellite. The data treatment used in analyzing routine rocketsonde measurements performed by a number of American and Soviet bases for over 20 years has evolved, as have the instruments themselves. The different data intercomparisons and the resulting adjustments have allowed for a decrease in the sources of errors, but have also introduced discontinuities into the measurement database. This has made the study of long-term temperature change very difficult.

Atmospheric trends, on a global scale, can only be determined with the help of satellite measurements. These measurements are, however, essentially radiometric and therefore need calibration by ground-based measurements. Rayleigh lidar could be the ideal instrument for taking these measurements, but it is first necessary to consider all possible sources of error and their nature. In this review, the different sources of error that may arise when taking temperature mea- 
surements by Rayleigh lidar will be studied in detail. The emphasis will be on the effects that these errors have on absolute measurements and their influence on the long-term database. It was a great help, in order to carry out this study, to be able to use several neighboring but different lidar stations.

\section{Method used}

To measure the density and then the temperature of the middle atmosphere, the Rayleigh backscattering of a monochromatic light pulse by air molecules is used. The possibilities of this method were demonstrated for the first time using mechanically modulated searchlights by Elterman (1951, 1953, 1954). Preliminary studies using laser pulses as monochromatic light were obtained by Kent and Wright (1970); however, these authors did not use these measurements to obtain significant geophysical results. It was not until December 1978 that Chanin and Hauchccornc (1981) obtained the first results based on density and temperature profiles from the lidar set up at the Haute-Provence $\mathrm{Ob}-$ servatory (OHP; $44^{\circ} \mathrm{N}, 6^{\circ} \mathrm{E}$ ) with the help of a system designed to mcasure alkali atoms.

The method used to measure temperatures by Rayleigh lidar has been described in detail in sevcral publications (Hauchecorne and Chanin 1980; Chanin and Hauchecorne 1984). As our object here is to attempt an in-depth study into the causes of error and their cvolution over the years, we will only briefly summarize this method.

$\Lambda$ short monochromatic light pulse is emitted vertically into the atmosphere by a laser. Data on the vertical structures of the atmospheric layers that are crossed by the beam are obtained by a time analysis of the number of backscattered photons collected by the telescope. The number of photons backscattered by a layer $\Delta z$ at altitude $z$ can be described in the following manner:

$$
N(z)=\frac{\begin{array}{c}
C_{1} N_{0} R_{q} S_{c} A(z) T^{2}\left(z_{0}, z\right) T_{\mathrm{opt}} \\
\times\left[\sigma_{m} h_{m}(z)+\beta_{a}(z)\right] m \Delta z
\end{array}}{\left(z-z_{0}\right)^{2}},
$$

with:

$C_{\mathrm{I}}: \quad$ Proportionality constant.

$T_{\text {epp }}: \quad$ Overall efficiency of the optics.

$N_{0}$ : $\quad$ Number of photons emitted.

$R_{q}: \quad$ Quantum efficiency of the photomultiplier.

$S_{c}: \quad$ Area of the optical collector.

$A(z)$ : Geometric factor (depending on the overlapping between the telescope field of view and the laser beam).

$T\left(z_{0}, z\right)$ : Atmospheric transmission between altitude $z_{0}$ and $z$ at the emitted wavelength.

$z_{0}: \quad$ Altitude of the lidar station.

$\sigma_{m}: \quad$ Molecular cross section of Rayleigh backscattering. $n_{m}(z)$ : Mass atmospheric concentration at altitude $z$.

$\beta_{a}(z)$ : Coefficient of Mie backscattering equivalent to $\Sigma_{r} \sigma_{a}(r) n_{a}(z, r)$.

$\sigma_{a}(r)$ : Mie backscattering cross section for particles of radius $r$.

$n_{a}(z, r)$ : Mass concentration of aerosol particles of radius $r$ at the altitude $z$.

$\Delta z:$

Thickness of the elementary backscattering layer (vertical spatial resolution).

$m$ : Number of laser shots.

Under the following conditions, it is possible to deduce the molecular density $n(z)$ of the atmosphere by the number of photons received $N(z)$ :

1) The scattering due to aerosols is negligible compared to molecular scattering,

$$
\beta_{a}(z) \ll \sigma_{m} n_{m}(z) ;
$$

2) The atmospheric transmission is constant or known throughout the entire zone,

$$
T\left(z_{0}, z\right)^{2}=T^{2}=\text { constant; }
$$

3) The telescope field of view is large enough to include the entire volume of the scattered beam,

$$
A(z)=1 .
$$

In that case, the expression (1) previously mentioned could be transformed into the following form:

$$
n(z)=\frac{C_{2}\left(z-z_{0}\right)^{2} N(z)}{\Delta z} .
$$

The coefficient $C_{2}$, which represents a normalizing constant, does not depend on the altitude, but its value may not be determined in an absolute manner as it depends on the power of the laser pulse, the quantum efficiency of the photomultiplier, and atmospheric and optical transmission. These parameters, particularly the atmospheric transmission, can vary from one shot to another. To obtain an absolute measurement of the density, the $C_{2}$ constant may be determined by identifying the density measured with a model $\{$ here, the CIRA 86 [COSPAR (Committee on Space Research) International Reference Atmosphere] at $40 \mathrm{~km}\}$, or with the help of a radiosonde measurement at $30 \mathrm{~km}$ given by the nearest meteorological station.

If one considers that the atmosphere is in hydrostatic equilibrium, a pressure profile can be determined from the density profile and an initial value of the pressure $P_{M}$ at the top of the profile $\left(z_{\text {top }}\right)$ :

$$
P(z)=\sum_{z}^{z_{\text {top }}}[n(z) g(z) \Delta z]+P_{M}\left(z_{\text {top }}\right) .
$$

The top of the density profile is determined when the signal-to-noise ratio becomes less than 3 . Taking the air mass as a constant value, the different parameters, 
air pressure $P(z)$, density $n(z)$, and temperature $T(z)$, can be linked together with the perfect gas law:

$$
\begin{aligned}
T(z)= & \frac{M P(z)}{R n(z)} \\
& =\frac{M \sum \sum_{z_{i}=z}^{z_{\text {top }}}\left[n\left(z_{i}\right) g\left(z_{i}\right) \Delta z\right]+P_{M}\left(z_{\text {top }}\right)}{R n(z)} .
\end{aligned}
$$

This equation shows that the temperature measurements do not depend on the normalizing constant $C_{2}$ [which links together the density $n(z)$ and the number of photons received $N(z)$ ]. Due to the exponential decrease of the pressure, the influence of the initialization pressure rapidly becomes negligible, and an absolute temperature measurement can be obtained. This is why more attention is devoted to the temperature than to the density parameter in long-term atmospheric studies performed by Rayleigh lidar.

\section{Accuracy of the instrument}

For any given lidar sounding, the accuracy in determining density is directly related to photon noise. This uncertainty in the number of photons detected is given by the Poisson law of statistics where the standard error is expressed as the square root of this number. Theoretical and experimental values of the variance (Appendix ) for the night of 18 January 1990, are given in Table 1. The relationship between these two quantities shows that the variance is less than $10 \%$. This result is encouraging if one considers that the photon counting is not absolutely accurate, due to the fact that a certain number of photons too close in time are not detected, or that photons may cause a double electrical pulse.

TABLE 1. Typical theoretical and experimental statistical standard errors (rms) obtained for one night at the CEL (see text).

\begin{tabular}{cccc}
\hline \hline & $\begin{array}{c}\text { Theoretical } \\
\text { standard } \\
\text { error }(\%)\end{array}$ & $\begin{array}{c}\text { Experimental } \\
\text { standard } \\
\text { error }(\%)\end{array}$ & Ratio \\
\hline $32-40$ & 0.0070 & 0.0069 & 1.02 \\
$40-48$ & 0.0294 & 0.0282 & 1.04 \\
$48-56$ & 0.1141 & 0.1053 & 1.08 \\
$56-64$ & 0.4209 & 0.3853 & 1.09 \\
$64-72$ & 1.690 & 1.573 & 1.07 \\
$72-80$ & 5.210 & 5.106 & 1.02 \\
$80-88$ & 13.80 & 12.53 & 1.10 \\
$88-96$ & 21.91 & 18.88 & 1.16 \\
$96-104$ & 24.24 & 22.04 & 1.10 \\
$104-112$ & 26.23 & 23.38 & 1.12 \\
$112-120$ & 27.49 & 24.06 & 1.14 \\
$120-128$ & 27.87 & 24.44 & 1.14 \\
$128-136$ & 27.83 & 24.79 & 1.12 \\
$136-144$ & 27.17 & 25.17 & 1.08 \\
$144-152$ & 29.44 & 25.50 & 1.15 \\
\hline
\end{tabular}

On top of the signal backscattered by the molecules $N(z)$, there is a parasite signal coming from the sky background $B_{\mathrm{SB}}$, and from the dark current $B_{\mathrm{PM}}$ of the photomultiplier:

$$
S(z)=N(z)+B_{\mathrm{PM}}+B_{\mathrm{SB}} .
$$

The uncertainty of the density measurement is then given by the following equation:

$$
\frac{\Delta n(z)}{n(z)}=\frac{\Delta S(z)}{S(z)}=\frac{\left(N(z)+B_{\mathrm{PM}}+B_{\mathrm{SB}}\right)^{1 / 2}}{N(z)} .
$$

At middle altitudes $(<60-70 \mathrm{~km})$, where the Rayleigh backscattering signal is predominant, and noise comes exclusively from the photon counting, the uncertainty is only related to the number of photons, but at higher altitudes the precision of the measurement degrades rapidly as a function of altitude:

$$
\frac{\Delta n(z)}{n(z)}=\frac{1}{[N(z)]^{1 / 2}}=\frac{C_{2}\left(z-z_{0}\right)^{2}}{[n(z)]^{1 / 2}} .
$$

The principal improvement enabling the reduction of this source of noise consists of increasing the number of photons collected by increasing the power of the laser $\left(N_{0}\right)$, the surface of the collector $\left(S_{c}\right)$, the detection efficiency $\left(R_{q}\right)$, and the optic transmission $\left(T_{\mathrm{opt}}\right)$. At higher altitudes, noise coming from the photomultiplier and the background light must also be taken into consideration. These elements should be reduced as much as possible. For the first source of noise, this is done by cooling the photomultiplier's photocathode by means of a water-cooled Peltier effect, thereby limiting the dark current to a value of about 25 pulses per second. The background light can be reduced by taking measurements at nighttime and filtering through space and time. The use of the lowest possible reception field of view allows for a geometrical separation of the signal from most of the noise. This solution, however, is limited very quickly because accurately fitting the telescope field of view with the scattering volume is a possible source of error. The background noise is also reduced by spectral filtering around the wavelength of the received signal. Use of a filter $f$ with a more selective bandpass $\Delta \lambda_{f}$ is often coupled with a less efficient optic transmission $T_{f}$. The best solution requires a compromise; if the wings of the filter are well blocked, then the choice of the optimum filter may be made taking into account the effect of the filter's two characteristics on statistical error:

$$
\frac{\Delta n(z)}{n(z)}=C_{3} \frac{\left(\Delta \lambda_{f}\right)^{1 / 2}}{T_{f}} .
$$

In our case, we have used an interference filter of $10 \AA$ and a field of approximately $10^{-4}-5 \times 10^{-4} \mathrm{rad}$, which reduces the noise to less than 500 pulses per second.

Daytime measurements have also been carried out using a Perot-Fabry interferometer, but as these mea- 
surements are still too irregular to be cntered into a long-term database, we will not refer to them.

The wavelength corresponding to the third harmonic of the Nd:Yag laser ( $355 \mathrm{~nm}$ ) could also be considered for use. The available laser energy is weaker at this wavelength, and the optics transmission less favorable than for visible wavelengths, but this is compensated by a larger cross section of Rayleigh backscattering and quantum efficiency of the detector (Fig. 1). Nevertheless, weaker performance levels are to be expected from this wavelength (a ratio of 2 in temperature error) than from a $532-n m$ wavelength because of a less efficient spectral and spatial filtering of the signal. The transmission of interferential filtcrs for UV wavelengths is not as good and the alignment of the emission and reccption telescopes is more difficult in the UV and may end up to be less accurate.

\section{Description of the instruments}

The first measurements were obtained by the lidar installed at the Haute.Provence Observatory (OHP; $44^{\circ} \mathrm{N}, 6^{\circ} \mathrm{E}$ ). This station has provided surveillance of the middle atmospherc, with a good temporal consistcncy (approximately 100 profiles per year), since June 1981. A second station, located at the Centre d'Essai des Landes at Biscarosse $\left(\mathrm{CEL} ; 44^{\circ} \mathrm{N}, 1^{\circ} \mathrm{W}\right)$ has helped to enrich this databasc since March 1986. A third instrument, installed on the French Navy ship the Henri Poincaré, demonstrates the highest-quality performances and has operated since May 1989. Finally, a

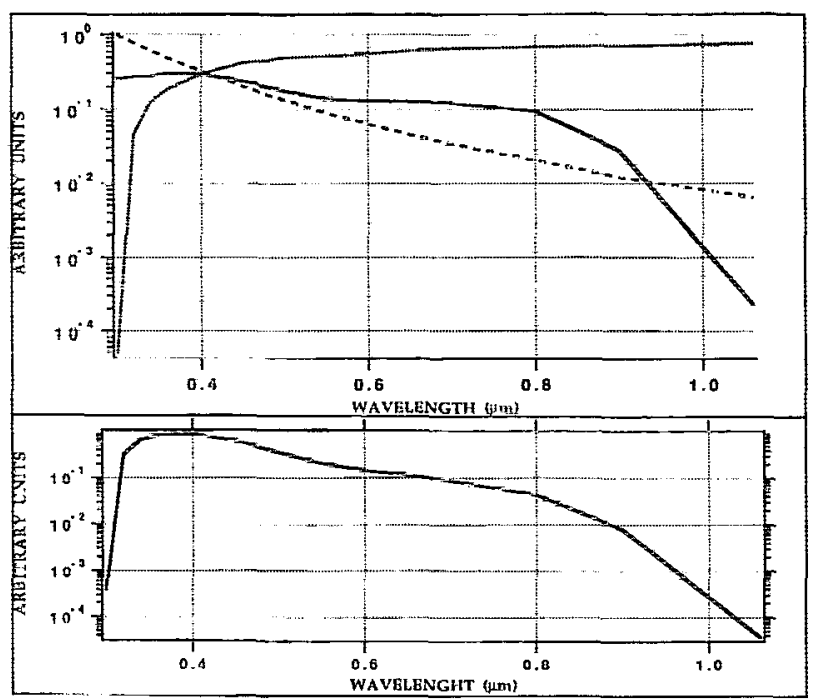

Fir. 1. Top: Rayleigh backscattering cross section (dash line), quantum efficicncy of the photomultiplier (full line), and atmospheric transmission for a clear atmosphere (Cole et al. 1965) along the path light from the ground to $30 \mathrm{~km}$ and from $30 \mathrm{~km}$ to the ground (dotted line). Bottom: Rayleigh lidar efficiency as a function of wavelength. mobile ground station, quite similar in conception to the ship version is operational since October 1991. These four instruments were designed according to the same principle and use the same algorithm for data calculation. The experience, however, of the OHP station 10-year operation, along with the technological evolution of the component elements, and most notably the lasers, have benefitted not only the more recently built stations (CEL, $H$. Poincaré, and the mobile lidar), but also the OHP station, which has been upgraded several times in the last decade. The characteristics of each of the four siations as well as their evolution in time are given in Table 2 and schematic diagrams are given in Fig. 2.

The four lidars all use the second harmonic of an Nd:Yag laser, which emits a light pulse of around 10 $\mathrm{ns}$ at the wavelength of $532.2 \mathrm{~nm}$. This emission is outside all absorption and resonance bands for atmospheric components above $30 \mathrm{~km}$. Taking into consideration the atmospheric and optical transmissions, the detection efficiency, the cross section of the Rayleigh backscattering, and the power of the available lasers, this choice allows for the maximal number of photons to be received.

The initial divergence of these lasers $\left(10^{-3}-10^{-4} \mathrm{rad}\right)$ is reduced by a factor of 10-15 with an afocal optical system. This emitter is placed either in the center of the reception mirror (CEL), next to it (OHP), or in the center of a group of receiving mirrors ( $H$. Poincaré and mobile lidar). The photons backscattered by the air molecules and particles are collected at the focus of these converging mirrors and transmitted to a detection box by means of mirrors (CEL), or by optical fibers (OHP, H. Poincaré, mobile lidar). In these detection boxes, the light of the backscattered signal is eventually separated into different channels, then filtered from the background light and detected by the photomultiplier in a "counting mode."

The "power" of the lidar is generally defined as the reception area multiplied by the average power of the laser. This term largely determines the accuracy and range of the system. A value of approximately $43 \mathrm{~m}^{2} \mathrm{~W}$ was attained for this parameter by the $H$. Poincaré lidar, thereby obtaining temperature profiles with a range of over $100 \mathrm{~km}$. This is greater than those obtained by the OHP and CEL lidars, which have a power of approximately $7 \mathrm{~m}^{2} \mathrm{~W}$. This increase was achieved using eight 50 -cm-diameter telescopes, constituting a $1.6-\mathrm{m}^{2}$ collecting surface, and six 150-mJ lasers, which alternately operate in groups of 3 at a $60-\mathrm{Hz}$ frequency.

At least two receiving channels are necessary to cover the altitude range from 30 to $100 \mathrm{~km}$. One for the lower atmospheric layers $(25-60 \mathrm{~km})$, and the other for higher altitudes ( $40-100 \mathrm{~km})$. Two different methods were used to obtain these two detection channels. The first one consisted of separating the signal in the reception box with a separating mirror (CEL). Recent configurations (OHP, H. Poincaré, mobile lidar) use 


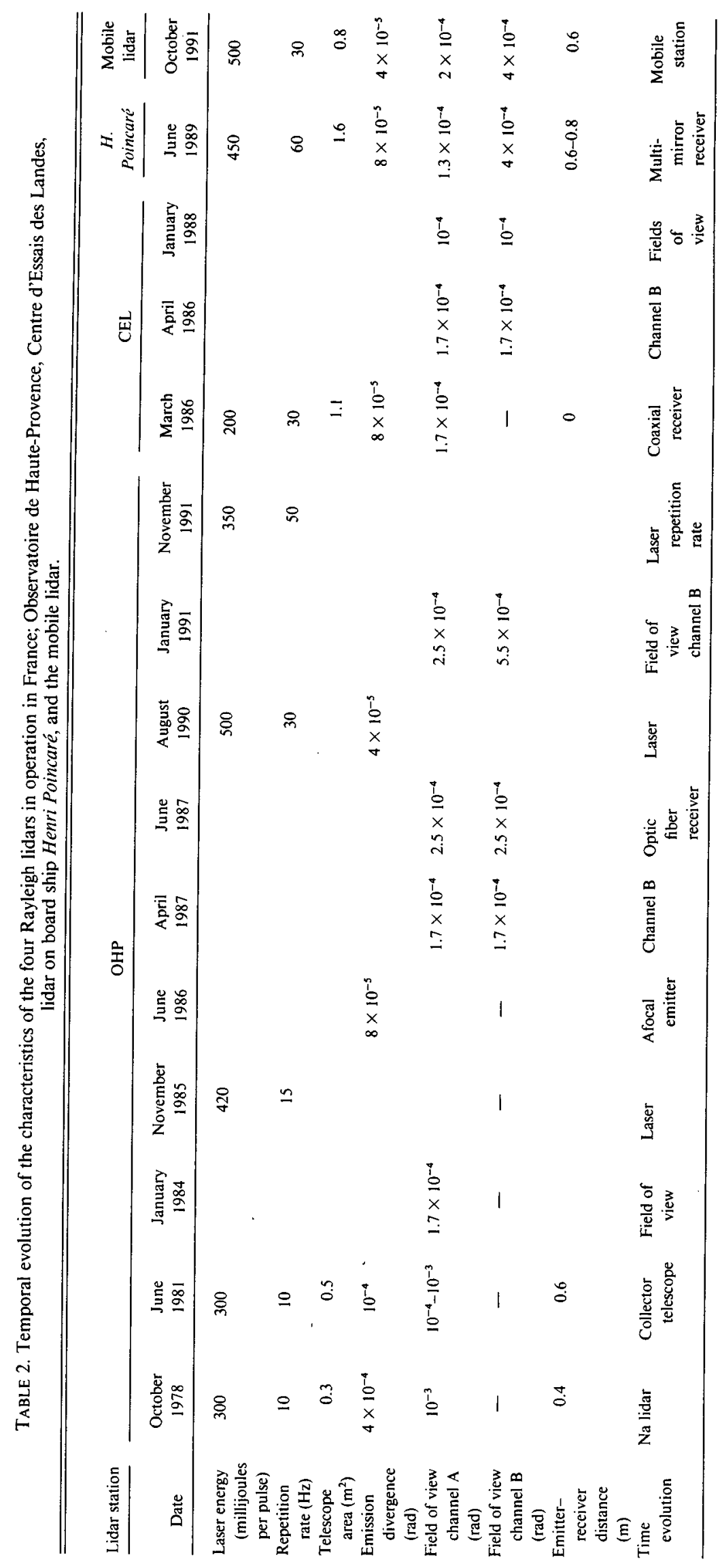



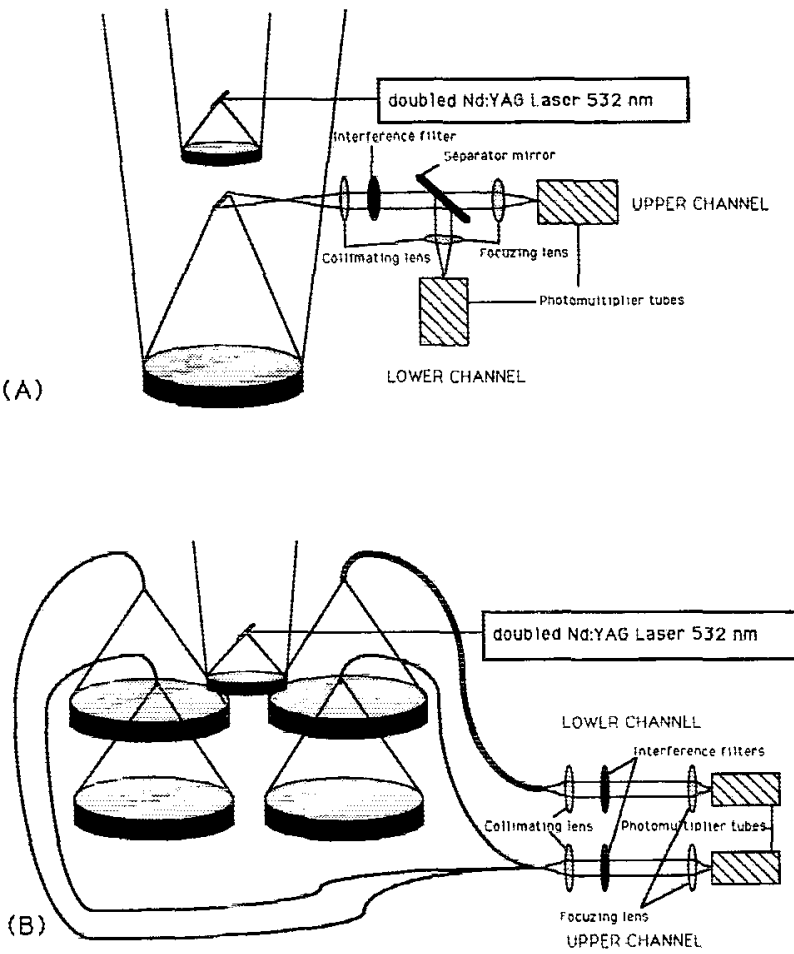

FIG. 2. Schematic diagram of the CEL lidar (type $A$ ) and of the other lidars (type B: OHP, H. Poincar', mobile lidar; which have respectively 2, 8 , and 4 received mirrors denoted $\mathrm{RM}$ ).

several reception telescopes with different fields of view for the two channels.

The time resolution, which is theoretically limited by the repetition rate of the laser pulses $(15-60 \mathrm{~Hz}$ depending on the station), is in fact determined by the initial integration time of the shots: $3 \mathrm{~nm}$ (summation of 3000 to 10000 consecutive shots) or more recently $1 \mathrm{~nm}$. The maximal vertical resolution is first defined by the duration of the electronic gate of the photon counting unit. Counting time is $2 \mu$ s for the first three stations, providing a $300-\mathrm{m}$ resolution. The mobile station can provide a $75-\mathrm{m}$ resolution; however, up until now it has been operated with the same resolution as the other lidars. It is always possible to degrade this initial resolution by grouping together several channels.

As the accuracy obtained is the result of a compromise between the integration period and the thickness of the layers sounded, the chosen temporal and spatial resolutions are adapted to the observation of the different geophysical phenomena under study. In the case of long-term trend studies, the temporal resolution is degraded for the entire sounding over one night. The vertical resolution used is $3 \mathrm{~km}$, which partly eliminates variances due to gravity waves. The mean accuracies obtained at the present time for a $3-\mathrm{km}$ resolution and a 3-4-h integration period are: less than $1 \mathrm{~K}$ from 30 to $70 \mathrm{~km}, 3 \mathrm{~K}$ at $80 \mathrm{~km}$, and $10 \mathrm{~K}$ at $90 \mathrm{~km}$. The same values are obtained with the $H$. Poincaré lidar at an altitude level $10 \mathrm{~km}$ higher.

It is very difficult to theoretically determine the exact performances of a lidar, as it depends both on the atmospheric transparency, which is never perfect, and the estimates (often optimistic) of the optical transmission and quantum efficiency of the detectors. Table 3 indicates the number of photons received at $60 \mathrm{~km}$ by three of the stations, estimated both by theoretical and experimental means, by comparing the results over three nights during which meteorological conditions were satisfactory. The OHP station, situated at $600-\mathrm{m}$ altitude, seems to be placed at the most favorable location, whereas the $H$. Poincare being on the ocean is the least favorable one, and results from the CEL station, as it is located on the Atlantic coast, fall between the two. The ratio between the theoretical and experimental value implies that a factor of at least 3 must be used in the theoretical calculations $\left(C_{1}\right)$ when sizing the power of the insirument in order to come as close as possible to reality.

\section{Sources of error}

The study of long-term trends in the thermic structure of the middle atmosphere is currently the subject of increasing interest, especially as these data are not very numerous. It is therefore necessary to be aware of the possible sources of error (random and systematic), and their evolution in time in order to evaluate their contribution to an apparent trend that would be purely instrumental. We will analyze the different possible sources of error one by one in the following paragraphs.

\section{a. Validity of hypotheses}

The assumption of a constant value for the mean atmospheric molecular mass is justified by the constant

TABLE 3. Number of received photons (in photoelectrons per pulse per microsecond) calculated and measured for a clear atmosphere at $60 \mathrm{~km}$ for lidars of OHP, CEL, and H. Poincaré.

\begin{tabular}{lcccc}
\hline \multirow{2}{*}{$\begin{array}{c}\text { Lidar } \\
\text { station }\end{array}$} & \multicolumn{2}{c}{ Number of photon counts } & Date & $\begin{array}{c}\text { Ratio theory/ } \\
\text { measure }\end{array}$ \\
\cline { 2 - 5 } & Theory & Measurement & 18 January 1991 & 2.8 \\
OHP & 0.31 & 0.11 & 19 February 1991 & 3.4 \\
CEL & 0.27 & 0.08 & 22 November 1989 & 4.7 \\
H. Poincaré & 0.89 & 0.19 &
\end{tabular}


mixing ratio of the major gases in the middle atmosphere $\left(\mathrm{N}_{2}, \mathrm{O}_{2}\right.$, and $\left.\mathrm{Ar}\right)$ and the negligible presence of water vapor. This has been proven up to $80 \mathrm{~km}$. Beyond this altitude, dissociation of $\mathrm{O}_{2}$ must be taken into account. This percentage of error is relatively low, but a $2 \%$ correction must be applied at $100 \mathrm{~km}$ and a $7 \%$ correction at $110 \mathrm{~km}$ (CIRA 1990).

Temperature profiles are obtained from dénsity profiles, based on the assumption that the atmosphere is in hydrostatic equilibrium. This is not true locally in turbulent layers, nor in the mesosphere where large fluctuations in the density may occur due to the breaking of gravity waves. But, taking into consideration the time and space resolutions used by the lidar, we can assume that this does not affect the mean atmospheric density. Assuming that the atmosphere is a perfect gas, Jenkins et al. (1987) calculated that the percentage of error in the temperature profile due to the presence of gravity waves could reach a value of $5 \%$; meaning approximately $1 \mathrm{~K}$ at more than $60 \mathrm{~km}$ for a wave with a $20-\mathrm{K}$ amplitude and an integration during $30 \mathrm{~min}$. When we take measurements corresponding to a $3-\mathrm{km}$ resolution and integrated during $3-4 \mathrm{~h}$ this error becomes negligible.

The atmospheric transmission at the wavelength that we use, $(532 \mathrm{~nm})$ is due to the Mie scattering, the Rayleigh scattering, and absorption by ozone. The attenuation due to the Mie scattering by aerosols, clouds, haze, and fog is the most difficult to estimate. Nevertheless, as the measurements are limited to a zone where this scattering does not exist, we can consider it as constant. Molecular scattering and absorption by ozone are only taken into account. The atmospheric transmission at altitudes between 30 and $100 \mathrm{~km}$ is greater than 0.995 (Cole et al. 1965). The attenuation is therefore very low and may be determined by an atmospheric model. The resulting error is very small and much less important than from other sources or from the photon noise.

To initialize the pressure profile, we must assume that the values of this parameter at the top of the profile

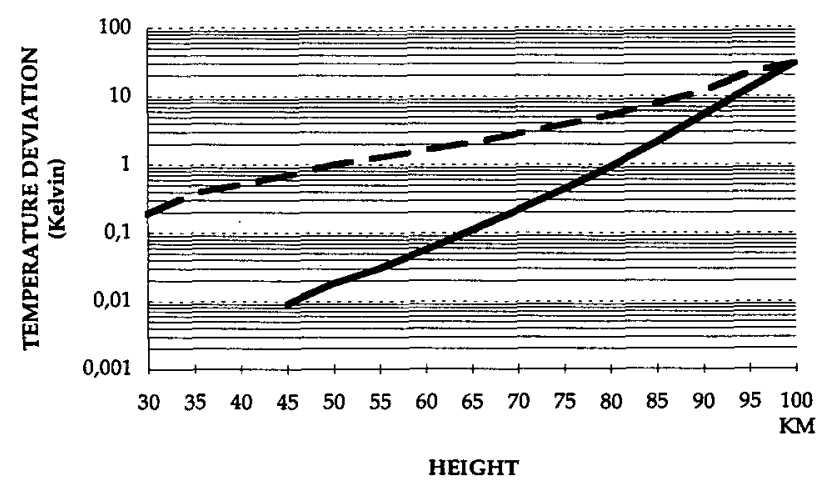

FIG. 3. Temperature uncertainty due to the pressure initialization (full line) compared to typical statistical noise (dash line). (i.e., for the last $10 \mathrm{~km}$ ) are, on the average equal to those of the standard atmosphere model (CIRA 1990) for the same altitude layer. The error due to this normalization may be estimated at $15 \%$ at the mesopause altitude (Hauchecorne et al. 1991). The calculation of uncertainty (Hauchecorne and Chanin 1980) shows that this error becomes rapidly negligible (due to the exponential decrease in the atmospheric pressure) as opposed to the noise statistic, which increases with the altitude (Fig. 3). As soon as we drop in altitude, the normalizing factor $P_{M}\left(z_{\mathrm{top}}\right)$ becomes rapidly negligible compared to the pressure at a given altitude. As an example, the error due to the normalization of the pressure profile at $110-\mathrm{km}$ altitude (which may reach a maximum of 20 or $30 \mathrm{~K}$ ) decreases by a factor of 10 to 100 at the altitudes of 95 and $80 \mathrm{~km}$, respectively. Therefore the temperature obtained, even with this normalization, can be considered as absolute and the estimated error consists mainly of the photon noise (section 4).

A systematic trend may exist because of the improvements made throughout the years to the range of the instrument. Currently around $60-70 \mathrm{~km}$, the error due to normalization may largely be considered as negligible. Normalization was made at $80 \mathrm{~km}$ during the first years of measurements. Then errors at 60 and $70 \mathrm{~km}$ were smaller with a factor of 30 and 3 , respectively, than the initializing error due to the uncertainty of the model in this height range. If we compare the climatological data obtained from 1984 to 1989 by lidar $\left(z_{10 p}=100 \mathrm{~km}\right)$ to the CIRA 86 model (Hauchecorne et al. 1991), we find differences of $\pm 10 \mathrm{~K}$ around 80 $\mathrm{km}$. This implies that during the first years of operation, systematic variations of 3 and $0.3 \mathrm{~K}$ could have been induced, respectively, at 60 and $70 \mathrm{~km}$, that is, for a linear increase in range, an apparent trend of 0.3 to $0.03 \mathrm{~K} \mathrm{yr}^{-1}$. To avoid this source of error, the profiles considered in the database are systematically limited upward to $20 \mathrm{~km}$ below the altitude of initialization.

Maximal variability at around $70 \mathrm{~km}$ generated by the occurrence of frequent mesospheric inversions has appeared in the climatology obtained by lidar. This result implies that lidars limited to a $70-\mathrm{km}$ range would have a greater uncertainty as regards normalization by model, which may not become negligible at $50 \mathrm{~km}$.

The altitude measurement is deduced from the wellknown velocity of light by the delay between the time when the light pulse is emitted and the time when the backscattered photons are received by the photomultiplier. The data acquisition system is initiated by the signal going out from an optical fiber that has collected part of the diffuse light of the emitted laser pulse. The correct synchronization between the laser pulse and the electronic sampling system could be a source of error that is difficult to detect with only one instrument and could induce a systematic bias in the altitude determination. We have used an electronic system that could give a calibrated light pulse of $6 \mu \mathrm{s}$ through an 
LED, to test the validity of the altitude determination within a resolution of $0.2 \mu \mathrm{s}(30 \mathrm{~m})$.

\section{b. Dynamic of the signal}

One of the difficulties encountered when measuring the atmospheric density on a large vertical scale is the dynamic of the signal. From 30 to $90 \mathrm{~km}$, an exponential decrease in density of more than a power of four is added to a variation of a factor of 10 in the solid anglc $\left(1 / z^{2}\right)$. No detector exists on the market with the eapacity of taking measurements within such a range. To solve this problem, two separate detection channels with different sensitivities are used in order to decrease the extent of the mcasurcd range. With the lascrs and telescopes available today, the number of photons backscattered by the atmospheric layers above $50 \mathrm{~km}$ is very low, and only represents an average of several photons per several thousands of shots. Measurcments of signals backscattered at higher altitudes is possible only with a photomultiplier used in a counting mode. For lower altitudes, however, the number of backscattered photons would be too high. A fraction of only several percent of the rciurning signal is therefore received by a second reception channel that is specially implemented for the lower layers of the profile.

When the actual number of photons received by the photomultiplier becomes too high, the phenomenon of saturation takes place and the photons received are not all accounted for. This is duc to the limitation of the bandpass ( $100 \mathrm{MHz}$ ) of the electronics. This produces a nonlinear response that is well represented by an exponential law with approximately $5 \%$ accuracy:

$$
N_{\text {count }}=N_{\text {received }} \exp \left(-\frac{N_{\text {received }}}{N_{\text {max }}}\right) .
$$

If we carefully analyze the correlation between the two reception channels (Fig. 4), a more complicated law is necessary to represent the photomultiplier's response:

$$
N_{\text {count }}-N_{\text {received }} \exp \left(-\frac{N_{\text {received }}}{N_{\text {max }}}-K N_{\text {received }}^{2}\right)
$$

When the number of photons received is low, they are not all counted by the electronic counting mechanism. This is due to the fact that the pulses generated are not all of the same amplitude and some are below the detection range. This correction affects less than $1-2 \mathrm{~K}$, and an error of less than $0.1 \mathrm{~K}$ can be anticipated. For an equal mean power laser, an increase in the frequency of the shots decreases the saturation of the detector. Lasers with a 60 - and $50-\mathrm{H} /$ repetition rate were therefore selected for the two most recent instruments.

\section{c. Noise extraction}

Despite the use of an inferential filter with a narrow bandpass, and a cooled photomultiplier, a parasite sig-

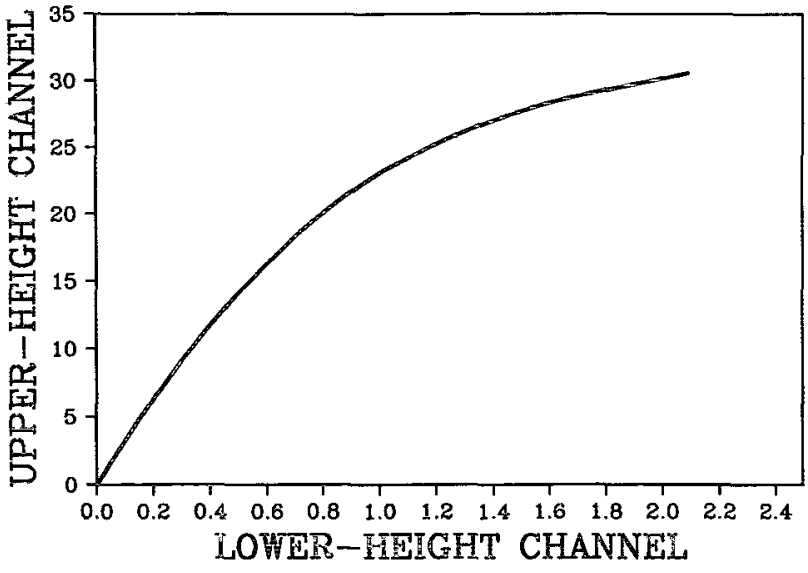

FIG. 4. Number of photons (photoelectrons per pulse per microsecond) received with the main channel as a function of the number of photons received with the other channel used for the lower altitudes. This figure gives the degree of saturation of the upper-height channel on 27 November 1989 on the lidar H. Poincaré; the lower-height channel is used as the reference.

nal is superposed to the signal backscattered by the molecules $N(z)$. This parasite signal is partly due to the sky background light $B_{\mathrm{SB}}(25 \mathrm{cps})$, and partly due to the photomultiplier's dark current $B_{\mathrm{PM}}(500 \mathrm{cps})$.

As this noise stems from a random process, it is characterized by a signal that is siatistically constant in time. If the integration period is long enough, a constant signal superposes the actual scattered signal. At altitudes where the signal can be considered negligible, the observation of a signal constanî with altitude can be anticipated:

$$
120<z<150 \mathrm{~km}, \quad S(z)=B_{\mathrm{PM}}+B_{\mathrm{SB}} .
$$

However, at this level of altitude, a time-dependent signal may often be observed. If the photomultiplier is not protected, the large scattering from the lower atmospheric layers causes an induced current on the photomultiplier cathode, which disturbs the measurements throughout the entire altitude range. To resolve this problem, it is necessary to protect the detector's photocathode. Three solutions are possible:

1) the use of a geometric shutter (by adjusting the alignment and increasing the distance between emitter and receiver),

2) the use of a mechanical shutter ("rotating pallet"),

3) the use of an electronic shutter (which controls the amplification of the photomultiplier).

The first solution has been rejected because it represents a source of error. In the very first experiments the second solution was used, but more recently electronic shutters were preferred to mechanical ones because of their greater flexibility, and especially due to the possibility of adjusting the shutter opening time according 
to the signal received and the region that is sounded. This method consists of applying an inverted voltage to the photomultiplier's second dynode in order to stop photoelectron acceleration. A certain amount of time is necessary, however, before the photomultiplier returns to stable operating conditions ( $100 \mu \mathrm{s}$ or $15 \mathrm{~km}$ ). Recent improvements in shutter functions have been made, and by simultaneously applying a weaker inverted voltage, but on several dinodes, this transition period is reduced to a value of around $10 \mu \mathrm{s}$, which corresponds to a distance of several kilometers. A slight slope $b_{s}(z)$ persists, however, in the signal over 120 $\mathrm{km}$ :

$$
S(z)=N(z)+B_{\mathrm{PM}}+B_{L}+b_{s}(z) .
$$

A statistical analysis (Fig. 5) characterizes this signal and shows that it can be normalized by a model using a parabolic function of time (or altitude):

$$
b_{s}(z)=A z+B z^{2} \text {. }
$$

But its determination must be made at an altitude where the scattered signal can be considered as negligible. As the range of altitude must be as large as possible to determine accurately this function, the analysis is made starting from the channel corresponding to an altitude $20 \mathrm{~km}$ beyond the top of the profile (100-120 $\mathrm{km})$ to the last measured channel $(150 \mathrm{~km})$. If the signal giving the noise level is incorrectly estimated, an error may appear in the temperature profile and cause disturbances of up to $20 \%$. This error becomes quickly negligible though at lower altitudes (1-2 K 10 $\mathrm{km}$ below the top of the profile) compared to the error due to photon noise $(10 \mathrm{~K}$ at $90 \mathrm{~km})$.

\section{d. Geometric factor}

In order for the atmospheric density to be deduced from the number of photons backscattered by mole-

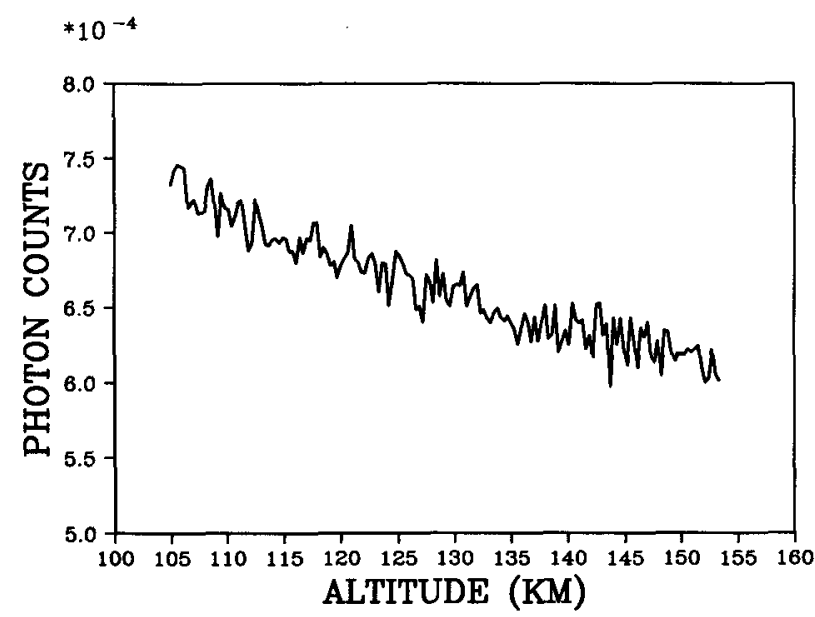

FIG. S. Statistical background noise (photoelectrons per pulse per microsecond) as a function of altitude obtained for an average of one week of measurement in May 1991 at the CEL.

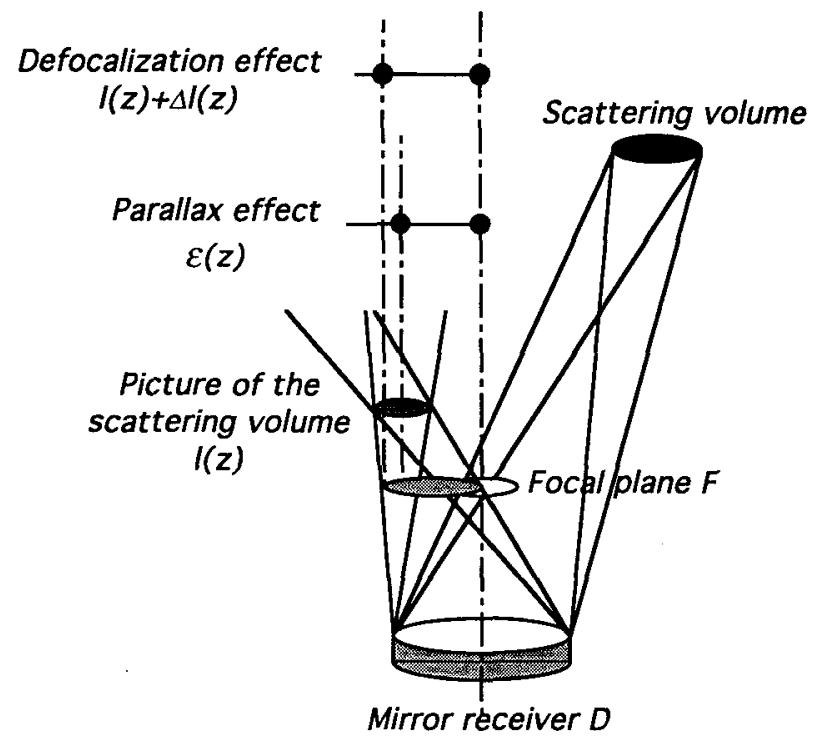

FIG. 6. Schematic diagram of the geometrical obstruction due to parallax and focal aperture obstruction effect in the focus plane of the received telescope.

cules, a perfect fit between the telescope field of view and the illuminated volume in the whole height range $(30-100 \mathrm{~km})$ must be guaranteed. The diaphragm (or optic fiber) of the telescope focus determines the field of view at infinity. But in reality, the divergence of the laser is not the only parameter to be considered, as there are two instrumental causes of enlargement of the focal image of the backscattered volume: the parallax effect and the focal aperture obstruction (nonfocusing effect).

A noncoaxial configuration of the emitter and receiver axes leads to a parallax effect. This is made apparent by a transversal movement $\epsilon(z)$ of the focal spot at the focus of the telescope, depending on the altitude of the sounded layer. This is demonstrated in a simplified manner in the following equation:

$$
\epsilon(z)=\frac{F \Delta}{z},
$$

with $F$ the focal distance of the telescope, $\Delta$ the distance between emission and reception axes, and $z$ the altitude studied.

Decreasing the distance $\Delta$ between the axes limits this effect. The ideal solution is a coaxial geometry.

Nevertheless, as the layers sounded are not situated at infinity, their image is not formed strictly at the same distance of the focal plane, depending on whether the photons are received from $30-$ or $100-\mathrm{km}$ altitude. Because of the focal aperture obstruction phenomena, the width of the beam in the plane of the diaphragm placed in the telescope focal plane is larger than the real image, and more so if we take into consideration the low-altitude atmospheric layers (Fig. 6). The following simplified equation demonstrates the impor- 
tance of this effect on the diameter of the image $l(z)$ of the scattering volume:

$$
\frac{\Delta l(z)}{l(z)}=\frac{D}{z \alpha}
$$

with $D$ the diameter of the collecting surface and $\alpha$ the divergence of the laser.

It is possible to theoretically calculate (Halldorson and Laderholc 1978) the geometric factor and the necessary optical components in order to enable this factor to be considered constant throughout the entire range of measure (30-100 km).

Because of parallax and focal aperture obstruction effects, as well as other defects that, to a smaller extent, affect the enlargement of the image at the telescope's focus ( turbulence, optic quality, thermic and mechanical tolerances, etc.), and because of uncertainty in alignment, the diameter of the diaphragm has been chosen oversized compared to the theoretical diameter for an infinite range. Oversizing of a factor of 2.5, 2, and 1.5 was chosen for the OHP (noncoaxial), $H$. Poincaré (quasi-coaxial), and CEL (coaxial) stations, respectively.

In the first experiments where temperature profiles were obtained, the field diaphragm was greatly oversized in order to guarantee alignment between the emission and reception axes. But, in order to improve the instrument's performance and to reach higher atmospheric layers, the noise due to the sky background was partly eliminated by reducing the field of view of the receiving telcscope. However, this improvement makes more difficult the good fit between the divergence of the laser beam and the telescope field of view and the guarantee to keep it so, over long periods of time; therefore, it could become a source of error. The inverse dependency of the alignment errors as a function of altitude, makes the lower altitudes more sensitive to this effect, and we can anticipate temperature measurements around $30-35 \mathrm{~km}$ to be slightly too high.

To ensure this alignment, the most commonly used method is to optimize the signal coming from altitudes of $40-50 \mathrm{~km}$ on an oscilloscope. However, the atmospheric transmission, laser energy, and detection efficiency vary from one shot to another, thereby causing this operation to become subjective; and it is extremely difficult to detect variations of less than several percent by eyc. Furthermore if the laser degrades, its divergence may increase, causing an even greater focal aperture obstruction effect. The quality of alignment can be checked objectively by using two receiving telescopes with different fields of view. The channel receiving signals from the lower layers $(25-70 \mathrm{~km})$ is less affected by noise coming from background light and can have a larger ficld of view and thereforc does not need such rigorous alignment. The channel used for higher altitudes, however, must have a smaller field of view, and its alignment with the laser beam is more difficult. The ratio of the number of photons in the common oper- ating zone $(40-70 \mathrm{~km})$ of the two channels should be constant for corresponding altitudes. If the alignment is incorrect, this ratio is characterized by an inverse function of the altitude, as demonstrated in the simplified equations of movement of the focal image and its change in size. This new configuration, which is installed on the OHP, H. Poincaré, and mobile lidars allows us to verify the alignment and to measure the geometric factor (Fig. 7). With this new possibility, a very small field of view, close to the theoretical values, can be used for the "high-altitude" channel, thereby improving the range and guaranteeing that this error will not exist for low-altitude measurements (30-35 $\mathrm{km}$ ) in the future. Concerning the previous measurements, this error is difficult to quantify on an a posteriori basis.

\section{e. The contribution of aerosols}

Generally speaking, the term coming from the Mie scattering due to aerosols $\beta_{a}(z)$ is added to the Rayleigh term $\beta_{m}(z)$ in the lidar equation. The number of photons received is multiplied by a factor $R$, known as the scattering ratio, and denined as follows:

$$
R=1+\frac{\beta_{a}(z)}{\beta_{m}(z)} .
$$

In the presence of aerosols, the determination of the density of the atmosphere by the measurement of backscattered photons is overestimated and is a function of $R$. The existing error $\Delta n(z)$ as a function of $R$ can be expressed as follows:

$$
\frac{\Delta T(z)}{T(z)}=\frac{\Delta n(z)}{n(z)}=R-1 .
$$

During periods of major volcanic eruptions, Mie scattering due to particles in suspension can contribute to the signal detected in backscattering up to altitudes of

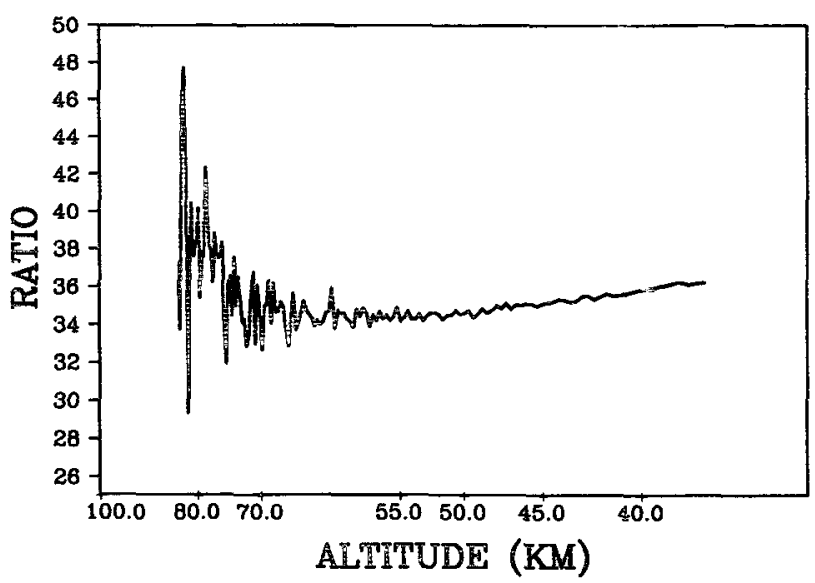

FIG. 7. Ratio between both channels as a function of the inverse of altitude in a case of a misalignment. 
$38 \mathrm{~km}$, as was the case for several months after the El Chichon eruption in 1982 (Lefrère et al. 1981). This represents a major limiting factor for the downward extension of the measurements. Recently developed solutions consist of using vibrational (Keckhut et al. 1990) or rotational (Hauchecorne et al. 1992) Raman backscattering of the nitrogen molecule to extend the temperature measurements in the lower part of the atmosphere, even in the presence of clouds and aerosols. These two methods each have their advantages, but measurements obtained using them are not yet numerous enough, nor do they extend over a long enough period of time to be able to be used in long-term studies.

When trying to accurately determine the altitude at which the presence of aerosols is negligible, we run into the problem of determining $R$ with a precision of less than $0.3 \%$ (Russell et al. 1989). One solution is to compare simultaneous measurements of Rayleigh and Raman backscattering (Fig. 8). But even though this solution is not based on any hypothesis on the nature and characteristics of the aerosols, it does not provide the necessary accuracy. In most cases (from 1984 to 1990 ), at $20 \mathrm{~km}$ the scattering ratio $R$ remained less than 1.1; the error induced is then around $2 \mathrm{~K}$ and the Rayleigh profiles were limited safely to $30 \mathrm{~km}$. After the El Chichón eruption (1982-83), it was necessary to set the lower limit at 40 and then $35 \mathrm{~km}$. At this date (in January 1992) the Pinatubo clouds have been localized below $32 \mathrm{~km}$ at our sites.

In the mesosphere, the problem of detecting aerosols is more difficult, as the atmospheric variability in this

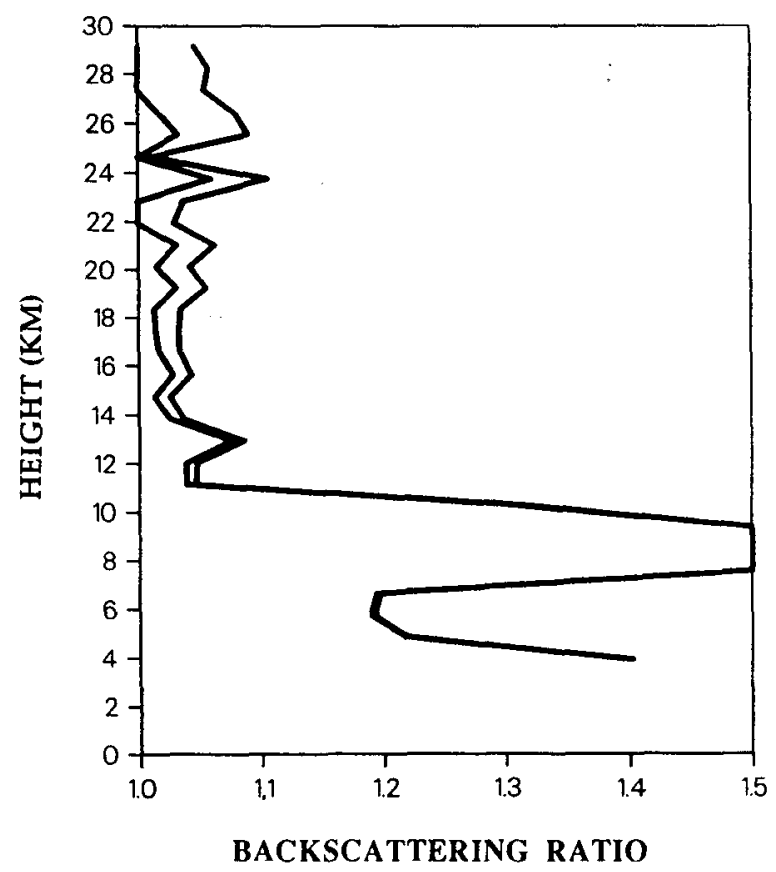

FIG. 8. Backscattering ratio at $532 \mathrm{~nm}$ using simultaneous Raman and Rayleigh signal on 9 August 1989.

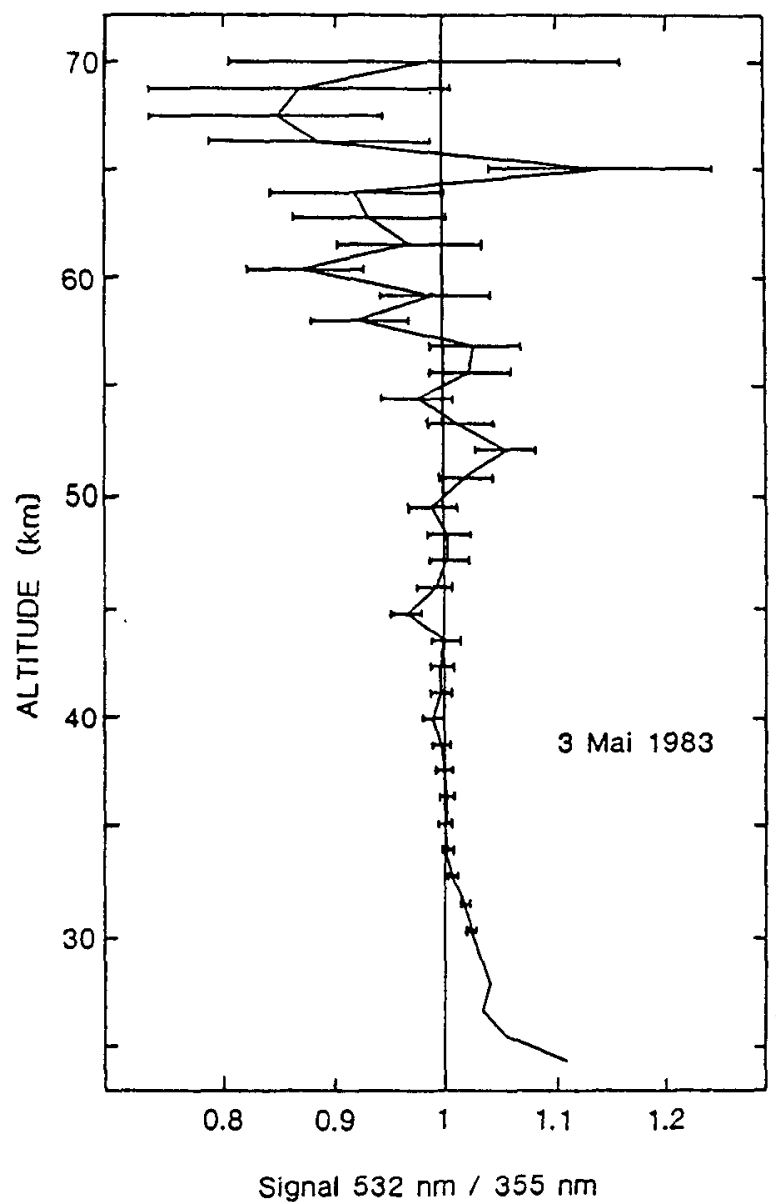

FIG. 9. Ratio of the backscattered signals obtained on 3 May 1983 at 532 and $355 \mathrm{~nm}$. The error bars represent \pm 1 standard deviation.

region is greater and very few instruments are capable of obtaining sufficiently accurate measurements at these altitudes. However, numerous lidar observations over the past decades have indicated the possibility of dust particles being present in the upper atmosphere. These conclusions have been made from the observation of an excess of backscattered light between 60 and $90 \mathrm{~km}$ when compared with a pure Rayleigh atmosphere as given by the U.S. 1966 atmospheric model (Fiocco and Smullin 1963; Bain and Sandford 1966; Fiocco and Grams 1966; Sandford 1967; Mac Cormick et al. 1967). Latitudes where such effects were observed vary from middle to high latitudes. A few times, these measurements coincided with the observation of noctilucent clouds in nearby areas and could be attributed to such phenomena known to occur frequently at high altitudes during the summer. Hansen et al. (1989) recently identified strong signals from a $1-\mathrm{km}$-thick noctilucent cloud at $83.2-\mathrm{km}$ altitude with a scattering ratio of 450 (at $589 \mathrm{~nm}$ ). These signals were identified simultaneously by Rayleigh lidar and sodium lidar from a high-latitude site (Andoya, Norway; $69^{\circ} \mathrm{N}, 16^{\circ} \mathrm{E}$ ). At 
latitudes of $45^{\circ} \mathrm{N}$, however, this type of phenomenon is rare (Thomas et al. 1984). However, at all latitudes a metcoric source is suggested to explain such a contribution because of the processes of ablation and condensation, or the formation of ion aggregates. For measurements taken from middle latitudes, or high latitudes out of the summertime, large differences between the atmospheric density and the models suggest that its interpretation in terms of aerosols could be simply explained by the use of an inappropriate reference model. The large variability, such as that due to a mesospheric inversion, is regularly observed by lidar from our latitudes and could lead one to believe that aerosols are present. Soundings from two wavelengths were carried out in 1983 by using the second and third harmonic of an Nd:Yag laser $(532 / 355 \mathrm{~nm})$. This made it possible to verify the negligible influence of particles from 35 to $70 \mathrm{~km}$ (Fig. 9). But the energy available at $355 \mathrm{~nm}$ was too low to provide a definite answer for the upper altitudes. As at that time, the range of the lidar systems was not reaching as far as today and this result was enough to validate measurements. Duc to the extended range of the new lidars, it is necessary to have a second look at this problem.

Assuming the presence of nonspheric aerosols, lidar soundings based on the simultaneous recording of the two polarization components of the backscattered light over 13 nights spread evenly throughout the year did not show any significant structures. Only one case, on 27 November 1989, showed two zones where the polarization ratio indicated a significant difference of $10 \%$ at $70-85 \mathrm{~km}$ (Fig. 10). No definite conclusion may be drawn from this isolated result, but it implies that this type of study should be undertaken anew, as the absence of backscattering layers in the upper mesosphere has never been verified in an absolute manner and could be a source of error at these altitudes.

\section{f. Summary of the impact of different sources of error}

This analysis shows that anticipated instrumental crrors are inferior to photon noise in most of the height range. And the random nature of these sources of noise makes us confident as to the determination of longterm trends. The different sources of error are localized in two distinct height ranges:

1) The extraction of background noise, the initialization of the pressure profile, and the photon noise may disturb temperature measurements at the top of the profile, which corresponds to the upper mesosphere. These sources of errors decrease very rapidly, however, in the middle mesosphere.

2) Sources of error in the lower part of the temperature profile are due to the presence of aerosols, the nonlinear correction of the photomultiplier, and the alignment of the emission and reception axes. As the accuracy of the measurements at this altitude is excel-
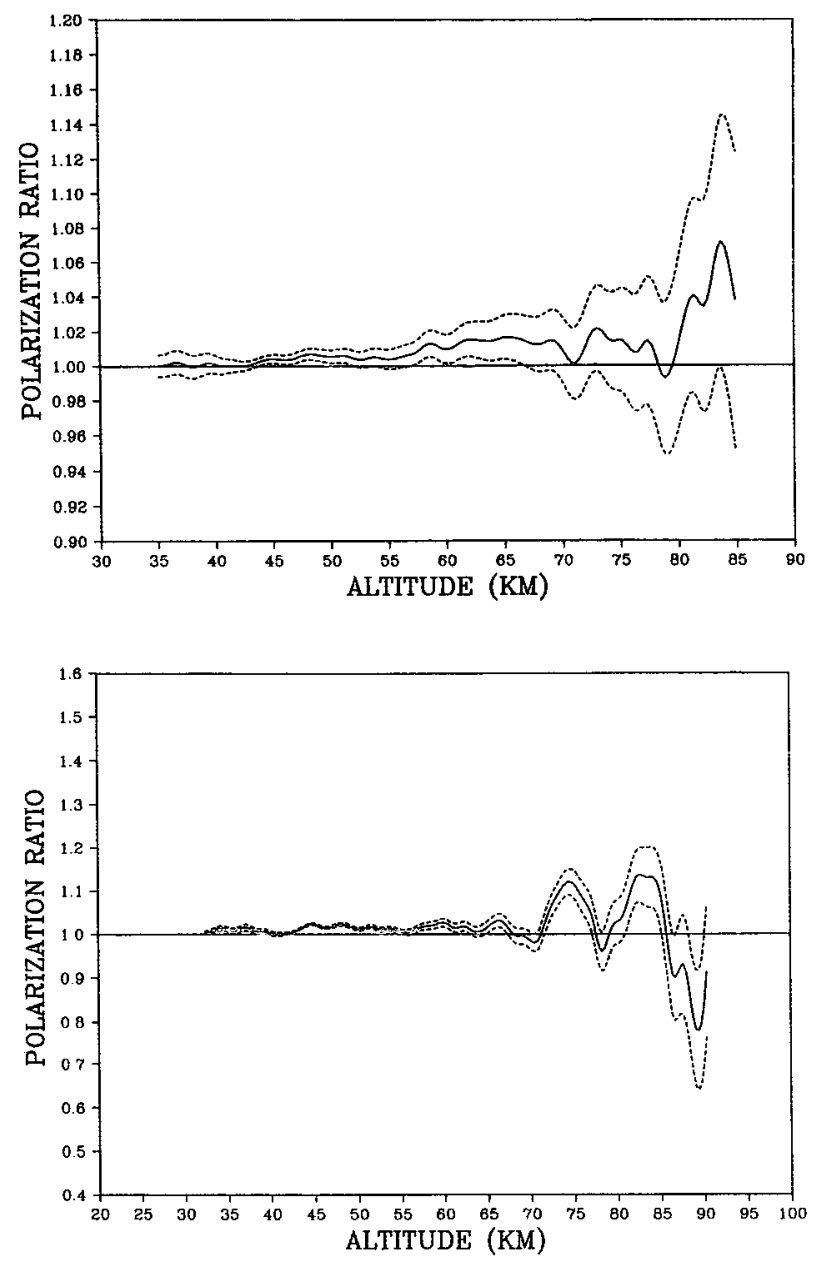

FIG. 10. (a) Mean polarization ratio as a function of height for 13 nights. The error bars represent \pm 1 standard deviation. (b) Same as (a) for the particular night of 27 November 1989.

lent, it is the most critical zone, as those errors cannot be neglected compared with photon noise. It is difficult to precisely quantify the effects of these disturbances on measurements, nevertheless the preceding analysis demonstrates that we can hope for accuracy of about $1 \mathrm{~K}$, but its value will be better given by comparison with other instruments.

For future uses, a certain number of improvements have been implemented. A diagram of the configurations of such a lidar as it can be conceived today is represented in Fig. 2b. Due to the central location of the emitter, the use of a multimirror collecting surface increases the "power" of the lidar and limits the parallax effect. With the use of optical fiber, the receiving telescopes and the reception box are separated mechanically. With two separate reception channels of different sensitivities and independent fields of view, it is possible to artificially reduce the dynamic of the signal to be measured, and to carry out measurements 
of the geometric factor as well as the nonlinear correction in the counting process.

In the following section, we propose to demonstrate, by comparing lidar measurements against those obtained by other methods, if any instrument bias exists, in particular below $50 \mathrm{~km}$, where the accuracy of measurement is very good.

\section{Comparison with other instruments}

Detection of sources of error by comparison with different instruments is not easy because there are few instruments that can take temperature profiles as accurately as a lidar. The first reported comparisons showed differences of several kelvins (Hauchecorne and Chanin 1980). This was considered satisfactory at the time, as these measurements were, for the most part, neither taken simultaneously nor from the same site. The number of measurements and instruments today is still very low, and searching for errors of the order of $1 \mathrm{~K}$ or less remains difficult.

\section{a. Rocketsonde}

Soundings by rocket were, for a long period of time, the only means of obtaining vertical temperature profiles with a good vertical resolution. The first comparisons made in 1978-79 and in 1981 (Hauchecorne and Chanin 1980; Chanin and Hauchecorne 1984) were quite satisfactory considering the distance between the two sites where measurements were taken ( 560 and $120 \mathrm{~km}$, respectively). Comparisons carried out more recently from a single site largely confirm this indication, especially under $60 \mathrm{~km}$ (Fig. 11). But it has been discovered that the validation of lidar soundings by rocket measurements is impossible as the differences observed between two sondes on board the same rocket were as great as those observed between the sondes and the lidar (Fig. 12). The repeatability of the results ob-

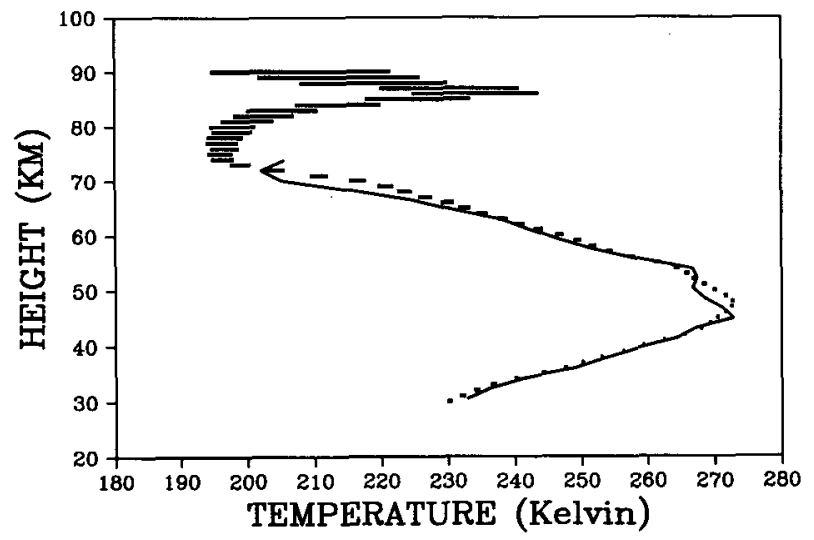

FIG. 11. Vertical temperature profiles obtained on 29 May 1986 with lidar (errors are represented by horizontal bars) and a rocketsonde (full line) at the CEL.

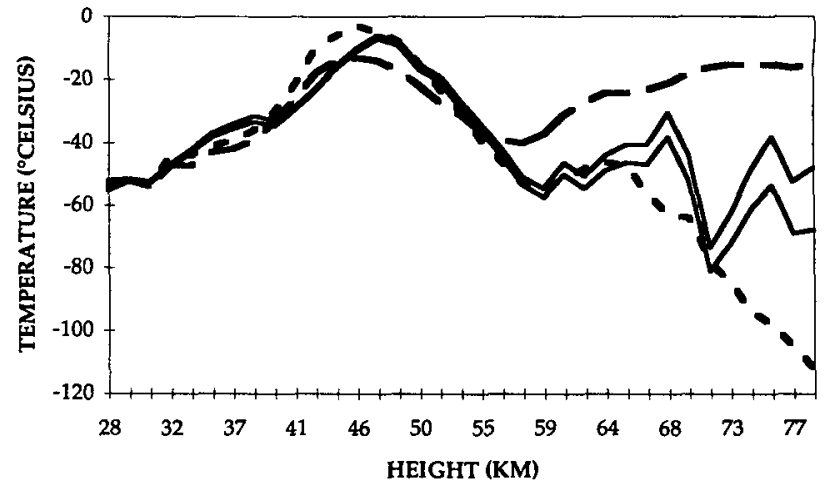

FIG. 12. Vertical temperature profiles obtained on 14 December 1989 on board the ship $H$. Poincaré with lidar given with \pm 1 standard deviation (full lines) and different sondes on board the same Super Arcas rocket (dashed lines).

tained by rocket sondes by Schmidlin (1981) have been estimated to be larger than $1.5 \mathrm{~K}$ below $60 \mathrm{~km}$.

\section{b. Falling spheres}

From January to March 1990, during the DYANA (Dynamic Adapted Network for the Atmosphere) campaign at the CEL station, a certain number of vertical temperature profiles were obtained simultaneously between 30 and $90 \mathrm{~km}$ by falling spheres (Schmidlin et al. 1991) and Rayleigh lidar. When the simultaneous profiles obtained from the two techniques are compared, the same structures are observed. It must be remembered that the spheres, unlike the lidar, allow an instantaneous measurement that can be slightly displaced compared to the vertical lidar sounding. Statistical comparisons of nine simultaneous temperature profiles demonstrated and quantified certain imperfections in the falling-sphere technique. Notably, a systematic bias at $65-75 \mathrm{~km}$, where the speed of the sphere passes from a supersonic speed to a subsonic one, and a strong dispersion occur below $45 \mathrm{~km}$ when, due to its low speed, the sphere is affected by vertical winds (Lubken et al. 1992). Between the altitudes of 45 and $65 \mathrm{~km}$, however, the two instruments register the same values with differences of less than $2 \mathrm{~K}$ with a $3-\mathrm{K}$ statistical dispersion $(95 \%)$.

\section{c. Satellite measurements}

It has been possible to make comparisons with temperatures obtained from radiance measurements taken aboard satellites. Certain instruments are of little interest in validating lidar measurements as they provide a too low vertical resolution. This is due to the large weighting function obtained with a nadir pointing instrument. Nevertheless, comparisons with the Stratospheric Sounding Unit (SSU) 27 channel showed satisfactory results considering the variability of the stratospheric winter temperature, and the fact that 
mcasurements are not rigorously taken simultaneously (Chanin and Hauchecorne 1984). A recent comparison with the SSU channel $47 \mathrm{X}$ (quite at the upper limit of the instrument), shows, however, a systematic difference of approximately $10 \mathrm{~K}$ (Aikin et al. 1991).

The technique of determining temperatures by $\operatorname{limb}$ radiance is independent of any exterior calibration, and provides much better vertical resolutions $(\sim 3 \mathrm{~km})$ [Limb Infrared Monitor of the Stratosphere (LIMS) and Solar Mesosphere Explorer (SME)]. Comparison between statistical averages obtained by the OHP lidar and the LIMS measurements from the Nimbus-7 satellite (Remsberg 1986) showed differences of less than $3.5 \mathrm{~K}$ between 37 and $64 \mathrm{~km}$. These differences are in good agrcement, considering the expected errors of the two instruments, the interannual atmospheric variability, and the respective zonal and local nature of the LIMS and lidar measurements.

The statistical comparison between lidar measurements and measurements taken on board SME (Clancy and Rusch 1989) during the period of 1982-85 was satisfactory $(1 \mathrm{~K})$ during the months of April and July. Noticeable differences at the end of 1983 and during the summer of 1984 , however, remain unexplained.

\section{d. Radiosonde balloon}

Unfortunately, comparisons between lidar measurements and radiosondes remain limited to low altitudes ( $30-35 \mathrm{~km}$ ). This is duc to the fact that balloon soundings rarely culminate above $35 \mathrm{~km}$, whereas lidar soundings are limited in the lower atmosphere due to the presence of aerosols (around $30 \mathrm{~km}$ ). Nevertheless, this altitude zone is a critical one because a number of sources of crror may be present in the temperature measurements by lidar (alignment of the lidar measurements: parallelism of the emission-reception axes, presence of aerosols, correction of linearity in the counting process). These comparisons are, therefore, of great interest. Temperatures measured by balloon

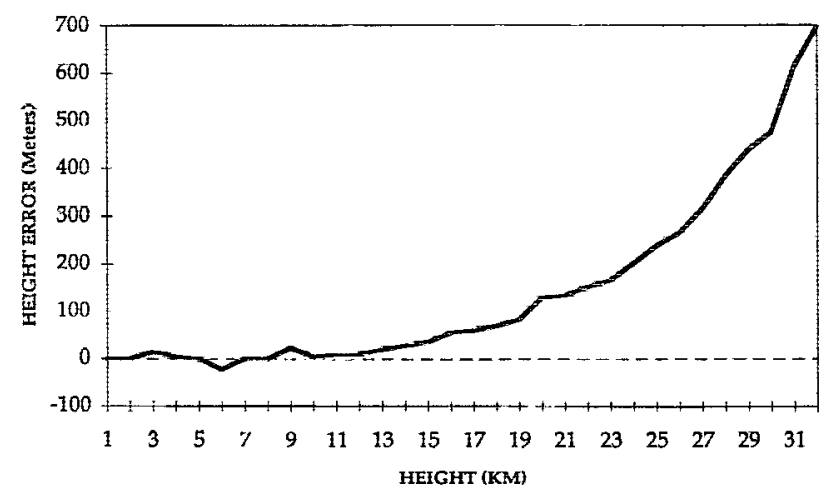

FIG. 13. Difference of altitude measurement of a radiosondc between the gcopotential height obtained with the pressure sonde located on board and geometrical altitude deduced from a radar trajectog. raphy.

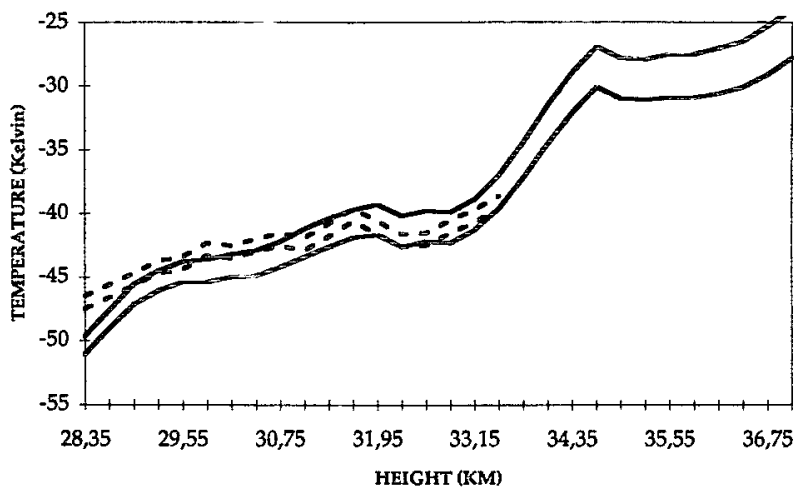

FIG. 14. Vertical temperature profiles obtained on 11 November 1990 on board ship $H$. Poincaré with lidar ( \pm 1 standard deviation in full line) and with a radio sounding obtained with a radar trajectography (dash lines represent temperature sonde and its uncertainty).

radiosonde are obtained by a thermistance-type captor, which is intrinsically accurate to $0.2-0.5 \mathrm{~K}$. However, comparisons of lidar temperature measurements and those obtained by balloon soundings at $30 \mathrm{~km}$ show greater differences. The principal drawback of balloon measurement is the inaccurate estimation of the altitude. Altitudes are determined from pressure using the hypothesis of hydrostatic equilibrium. The geopotential altitude that is calculated depends on the pressure measurement and its precision. The pressure sensor has an inaccuracy of around $0.3 \mathrm{hPa}$. Given that and the fact that this parameter varies exponentially in the atmosphere, this inaccuracy can lead to an incertitude of several hundred meters (Fig. 13), which would mean a difference in temperature of $1-3 \mathrm{~K}$. An error of several kelvins in the estimated temperature at $30 \mathrm{~km} \mathrm{(1-6}$ $\mathrm{K}$ ), was experimentally obtained from several simultaneous soundings by different manufacturers (Nash and Schmidlin 1987). This includes the error due to the information supplied by the pressure sensor $(3 \mathrm{~K})$, as well as from the measurement in itself $(3 \mathrm{~K})$.

When the altitude of the balloon is radar monitored, however, a true geometric altitude is obtained that is accurate to within a few dozen meters. Very few soundings have been carried out simultaneously and within close proximity by lidar and radar-monitored balloons. They have only been made by the CEL station and the ship H. Poincaré. All the same, each time these comparisons show close concordance at $30-35 \mathrm{~km}$ with a difference of never more than $1 \mathrm{~K}$ (Fig. 14).

\section{e. Comparison between lidars}

From previous studies, we can see that the validation of lidar measurements is very difficult as no standard instrument of equal precision exists. One solution for further validation consists in comparing temperatures obtained by two lidar stations at the same moment. It is obvious that errors in the hypothesis or errors related 


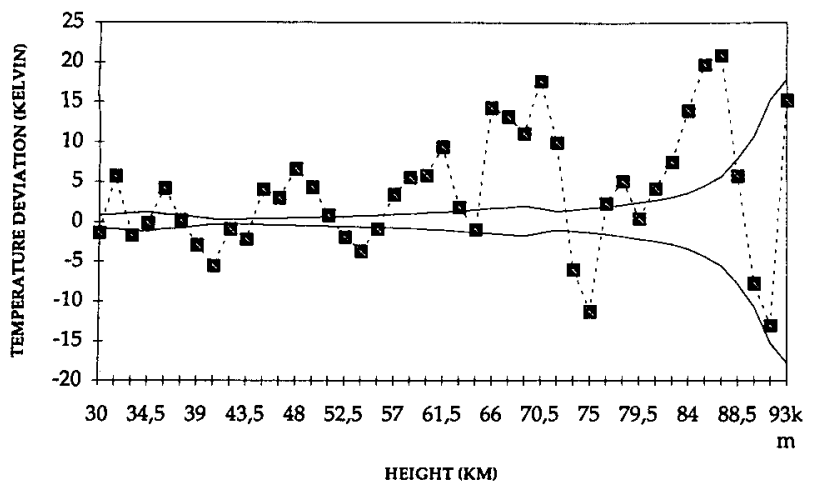

FIG. 15. Difference between simultaneous vertical temperature profiles obtained at the CEL and with the lidar on board ship $H$. Poincaré located at Brest $(500 \mathrm{~km}$ north of the CEL) on 12 June 1990 (black square). Full lines represent the \pm 1 standard deviation.

to the technique itself will not show in this type of study, but as the stations are never absolutely identical, certain systematic errors, if they exist, should appear, such as: misalignment, incorrect estimations of background light, and incorrect estimation of photomultiplier nonlinearity.

Lidar temperature profiles at a distance of $500 \mathrm{~km}$ were obtained simultaneously at the CEL station and the OHP or at the CEL and at Brest H. Poincaré. Individual case studies show differences from one day to the next between the sites that seem to be of a random nature. An example taken on 12 June 1990, during a season when wave activity is relatively low, is shown in Fig. 15a. The difference in the measurements carried out at each station oscillates around a zero value as a function of altitude. These disturbances, manifested by the differences between the two profiles, are clearly coming from the propagation of gravity waves. In this particular case, it is possible to discern an increase in the amplitude of these exponential fluctuations and a vertical wavelength of $8 \mathrm{~km}$. This is concordant with the characteristics of gravity waves.

A statistical study of large quantities of measurements is certainly useful to estimate the differences that may exist between two lidar stations. It is also necessary that the profiles be integrated over several hours in order to eliminate most of the variance due to gravity waves, which are the principal source of spatial variance for scales of this type. The statistical study of 169 simultaneous profiles at the OHP and CEL stations ( situated at the same latitude), leads to a very good concordance above $45 \mathrm{~km}$ considering the noise level at these altitudes $(90 \%)$. Below this altitude, a difference of less than $2 \mathrm{~K}$ has been observed (Fig. 16); which seems to indicate a higher temperature at OHP; this fact may or may not have a geophysical interpretation. Anyhow, the result of this comparison has led to the conclusion that, if a systematic bias does exist at one of the stations, it does not exceed this value. Large variability is present in winter in both series, but the simultaneous value presents a good agreement. However, systematic variations of several kelvins were observed during two summer periods (Fig. 17). With our knowledge of the horizontal variability at these distances, in summer, we cannot attribute these variations to a geophysical origin. After examination of different possible causes, the differences observed between these two instruments during the summer of 1987 and in August 1988, could stem, respectively, from the increase in the divergence of the CEL laser during this first period, and the use of incorrect alignment procedures at the OHP station in the second one.

For these reasons, it would be desirable to carry out studies between lidars at closer distances. This type of study was recently made possible with the CEL lidar when the $H$. Poincaré was transiting in the Gulf of Gascogne (180 and $100 \mathrm{~km}$ from the CEL station). These comparisons of simultaneous soundings integrated over several hours made it possible to eliminate only part of the variance due to gravity waves. It clearly seems that the variations in the measurements taken by these two lidars decrease with the distance between them. Differences of less than several kelvins observed below $70 \mathrm{~km}$ correspond to oscillations that could be attributed to gravity waves. A difference of around $10 \mathrm{~K}$ was observed between these same two stations above $70 \mathrm{~km}$ on 10 and 11 July 1990 (Fig. 18 and 19). This can, however, be attributed to a predominant inversion layer that was clearly visible over one of the two sites. The altitude of this anomaly is coherent with this interpretation. These case studies do not indicate any systematic errors.

The mobile station, currently located at the OHP station, has allowed us for the first time in November 1991 to verify the quite perfect similarity between

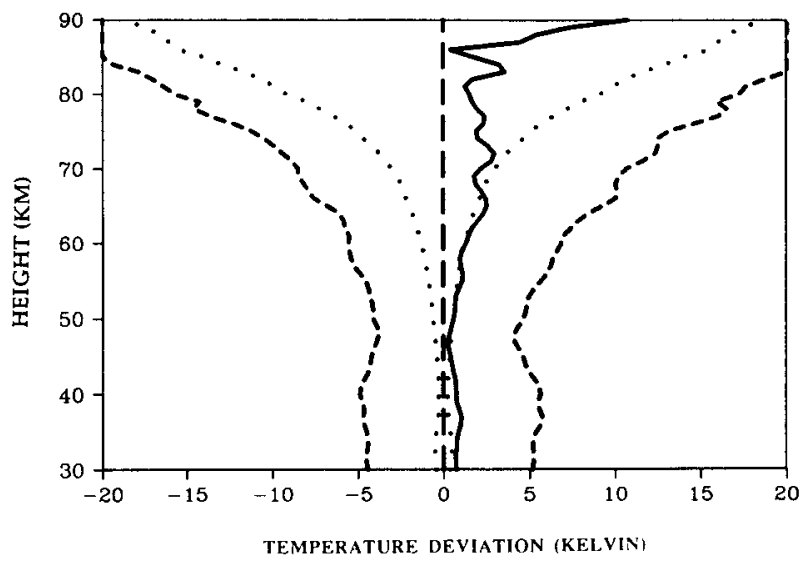

FIG. 16. Statistical comparison between 169 simultaneous profiles obtained from 1986 up to 1990 at the CEL and at OHP independently of the season. Temperature deviation (full line), statistical error with \pm 1 standard deviation (dotted lines), and standard deviation of the temperature deviation (dashed lines) are represented. 


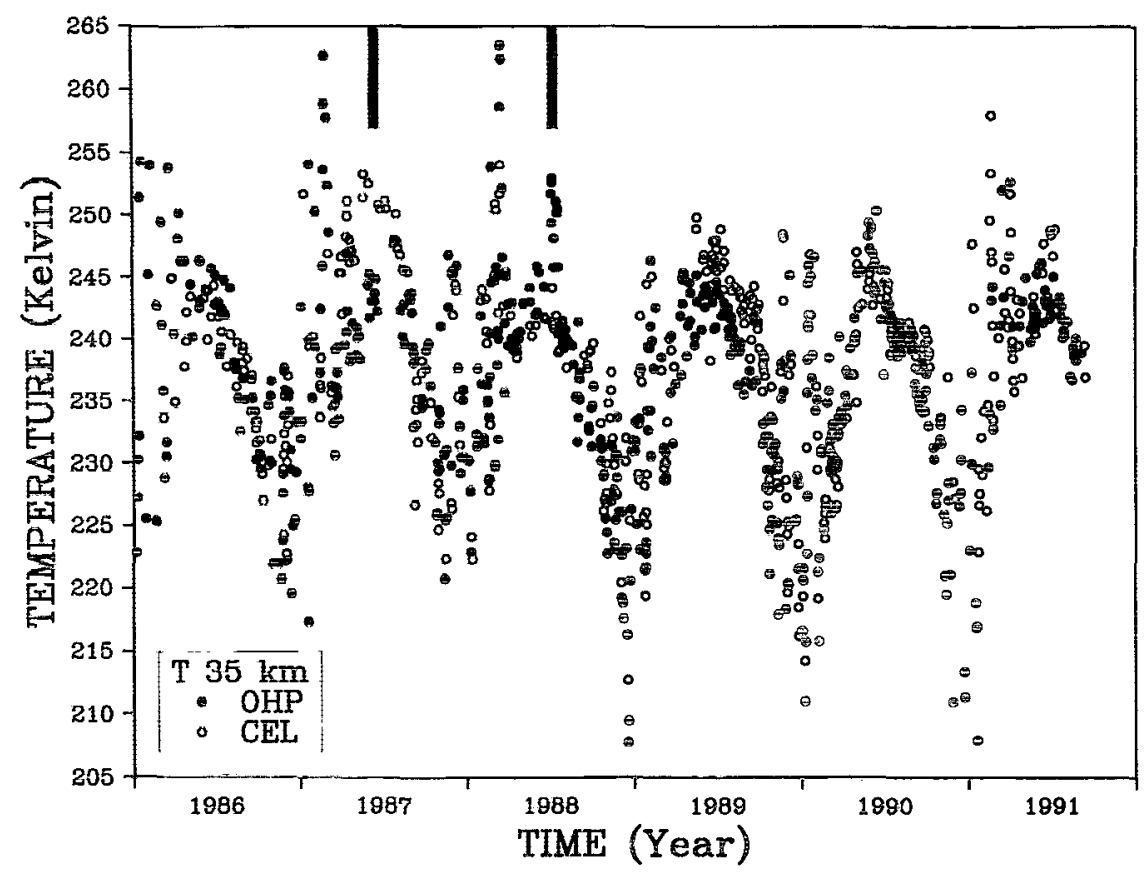

FiG. 17. Tcmpcrature at $35 \mathrm{~km}$ as a function of time given by both lidar located at the OHP and at the CEL.

measurcments taken by two lidars situated on the same site every time that they operate simultaneously. This result is extremely important and it justifies the attribution of the previously observed variations between lidar measurements to natural and real atmospheric temperature inhomogeneities at distances of $100 \mathrm{~km}$ (Fig. 20).

\section{Conclusions}

This study proves the fidelity of its measurements. Furthermore, it appears that the evolution of the instrument has increased its possibilities without compromising accuracy. The validation of Rayleigh lidar

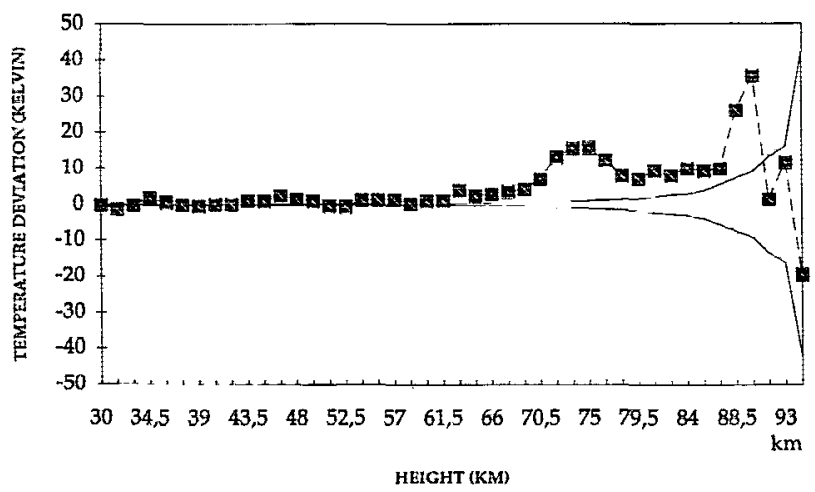

FIG. 18. Same as Fig. 15 on 11 July 1990 when the ship H. Poincaré is located on the Gulf of Gascogne $180 \mathrm{~km}$ away from the CEL. measurements by the use of other instruments remains difficult because no standard instrument of equivalent sensitivity and accuracy exists. Generally speaking, there is a close concordance between different measurements, and comparison between Rayleigh lidars seems to be a promising solution for checking new instruments. Variations in temperatures observed by the different lidars when not collocated can in general be attributed to horizontal differences of geophysical origin. However, we observed two cases where either a bad alignment procedure, or the degradation of the laser divergence induced a large systematic error. Thus a careful procedure should be followed and a comparison between collocated instruments is advisable. In

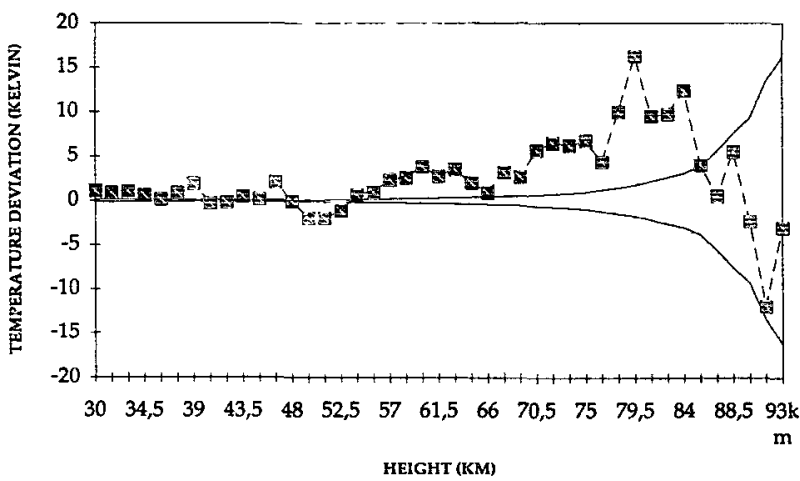

Fig. 19. Same as Fig. 15 on 10 July 1990 when the ship H. Poincaré is located on the Gulf of Gascogne $100 \mathrm{~km}$ away from the CEL. 


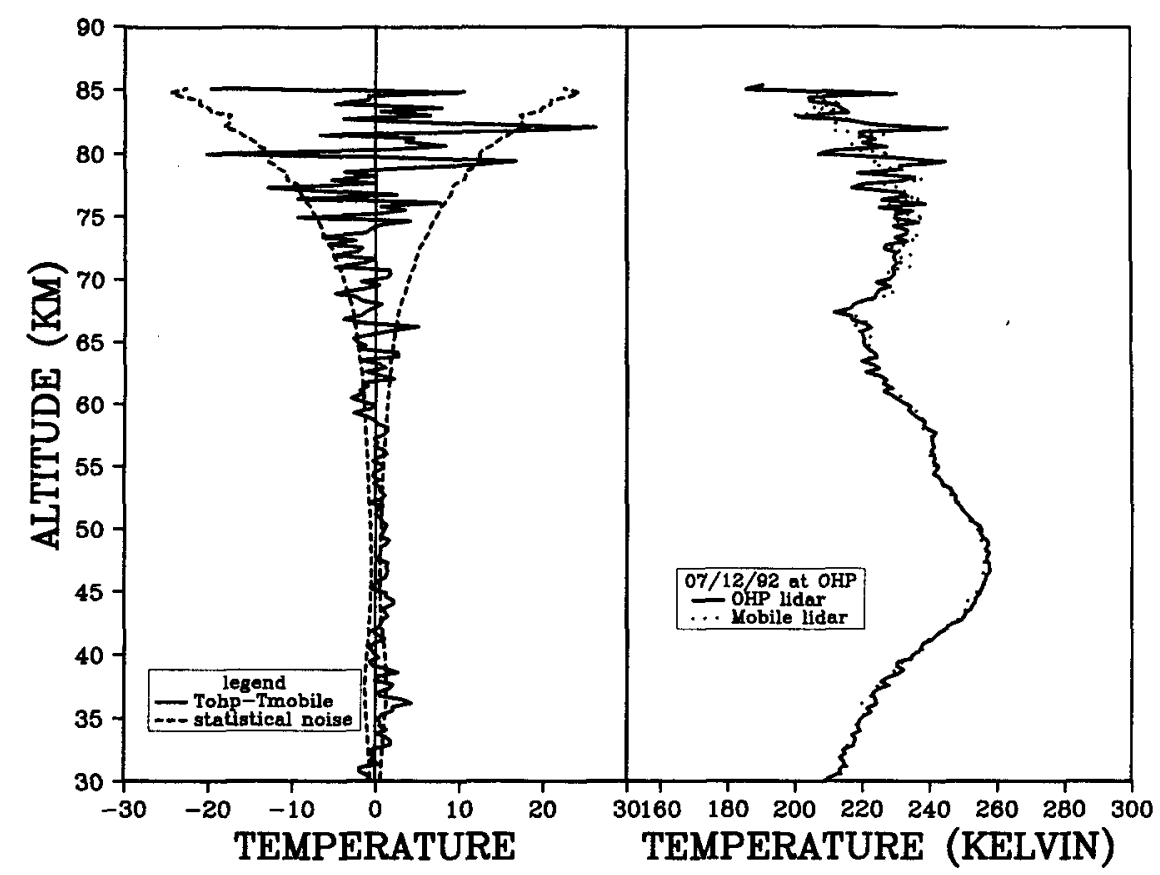

FiG. 20. Comparison between simultaneous profile obtained in the same site with the permanent OHP lidar and the mobile lidar. The difference between both measurements is represented in the left side compared with the total statistical noise.

the future, with the mobile lidar, it will also be possible to vary the distances between stations and thereby study the horizontal structure as well as the temporal evolution of various geophysical phenomena.

Climatological surveillance today in the upper atmosphere necessitates the use of an instrument that can provide absolute measurements of extreme precision. The Rayleigh lidar, which provides an absolute temperature measurement and does not need adjustment or external calibration seems like an ideal candidate. Another major application of these results is the use of a network of such lidars for validation of satellite data.

Acknowledgments. We wish to acknowledge the contribution of all the Rayleigh lidar team of the Service d'Aéronomie and especially Frederic Fassina, Anne Garnier, Jacques Porteneuve, and Claude Souprayen for their help in improving the Rayleigh lidar technique.

\section{APPENDIX \\ Determination of an Experimental Value of the Variance Due to the Statistical Noise}

It is possible to experimentally estimate the variance in the measurement due to statistical noise over the course of one night, taking into consideration the variance of the signal between two altitudes, separated by a thickness $\Delta z(300 \mathrm{~m})$. To eliminate the component that could be attributed to short vertical wavelengths, we can refine the calculation by taking into equal consideration two consecutive recordings $(\Delta t=3 \mathrm{~nm})$. The wave component varies in a coherent manner from one recording to another, whereas the noise component is incoherent. The following equation measures the variance $\sigma_{\text {mes }}^{2}$, which can be compared to the wellknown theoretical value $\sigma_{\text {theor }}^{2}$ :

$$
\sigma_{\text {mes }}^{2}(z)=\frac{4}{3} \sum_{t=1}^{n}[\Delta \varphi(t, z)-\Delta \varphi(t+\Delta t, z)]^{2},
$$

with,

$$
\begin{aligned}
& \Delta \varphi(t, z) \\
& \quad=\frac{S(t, z)-1 / 2[S(t, z-\Delta z)+S(t, z+\Delta z)]}{S(t, z)+1 / 2[S(t, z-\Delta z)+S(t, z+\Delta z)]},
\end{aligned}
$$

and

$$
\sigma_{\text {theor }}^{2}(z)=\frac{1}{N(z)}
$$

\section{REFERENCES}

Aikin, A. C., M. L. Chanin, J. Nash, and D. J. Kendig, 1991: Temperature trends in the lower mesosphere. Geophys. Res. Lett., 18, 416-419.

Bain, W. C., and M. C. W. Sandford, 1966: Light scatter from a laser 
beam at heights above $40 \mathrm{~km}$. J. Atmos. Terr. Phys., 28, 543552.

Chanin, M. L., and A. Hauchecorne, 1981: Lidar observation of gravity and tidal waves in the stratosphere and mesosphere. $J$. Geophys. Res., 86, 9715-9721.

- and $-1984:$ Lidar studies of temperature and density using scattcring. Map Handb., 13, 87-89.

- - and - and N. Smires, 1985: Contribution to the CIRA model from ground-based lidar. Map Handb., 16, 305-314.

- N. Smires, and A. Hauchecorne, 1987: Long-term variation of the temperature of the middle atmosphere at mid-latitude: Dynamical and radiative causes. $J$. Geophys. Res., 92, 933-941.

- A. Hauchecorne, and N. Smires, 1990: Contribution to the new reference atmosphere from ground-based lidar CIRA 1986 , Part II. Adv. Space Res., 10, 211-216.

Clancy, R. T.. and D. W. Rusch, 1989: Climatology and trends of mesospheric $(58-90 \mathrm{~km}$ ) temperature based upon 1982-1986 SME limb scattering profiles. J. Geophys. Res., 94, 3377-3393.

Cole, A. E., A. Court, and A. J. Kantor, 1965: Model atmosphere. Handbook of Geophysics and Space Environments, S. L. Valley, Ed., McGraw.Hill, 196-197.

COSPAR International Reference Atmosphere 1990: Part Il: Middle atmosphere models. Adv. Space Res., 10.

Elterman, L. B., 1951: The measurcment of stratospheric density distribution with the searchlight technique. J. Geophys. Res., 56, 509-520.

-. 1953: A series of stratospheric temperature profiles obtained with the searchlight technique. J. Geophys. Res., 58, 519-530.

- 1954 : Seasonal trends of temperature, density, and pressure to $67.6 \mathrm{~km}$ obtained with the searchlight probing technique. $J$. G'ophys. Res., 59, 351-358.

Finger, F. G., M. E. Gelman, J. D. Wild, M. L. Chanin, A. Hauchecorne, and A. J. Miller, 1993: Evaluation of NMC upper stratospheric temperature analyses using rocketsonde and lidar data. Bull. Amer. Meterr. Soc., 74, 789-799.

Fiocco, G., and L. D. Smullin, 1963: Detection of scattering layers in the upper atmosphere $(60-140 \mathrm{~km})$ by optical radar. Nature, $199,1275-1276$.

- , and G. Grams, 1966: Observation of the upper atmosphere by optical radar in Alaska and Sweden during the summer 1964. Tellus, 18, 34-38.

Gille, S. T., A. Hauchecorne, and M. L. Chanin, 1991: Semidiurnal and diurnal effects in the middle atmosphere as seen by lidar. J. Geophys. Res. 96, 7579-7587.

Halldorson, $F$, and J. Langerholc, 1978: Geometrical form factors for the lidar function. Appl. Opt., 17, 240 244.

I lansen, G., M. Serwazi, and U. Van Zahn, 1989: First detection of noctilucent cloud by planetary waves in the stratosphere. Geophys. Res. Lett., 16, 1445-1448.

Hauchecorne, A., and M. L. Chanin, 1980: Density and temperature profiles obtained by lidar between 35 and $70 \mathrm{~km}$. Geophys. Res. Lett., 7, 565-568.

- , and - -1982 : Mid latitude ground-based lidar study of stratospheric warmings and planetary waves propagation. $J$. Atmes. Terr. Phys., 44, 577-583.

$\longrightarrow$, and $-1983:$ Mid latitude lidar observations of planetary waves in the middle atmosphere during winter of 1981-1982. J. Geophys. Res., 88, 3843-3849.

-_-, —_, and R. Wilson, 1987: Mesospheric temperature inversion and gravity wave breaking. Geophys. Res. Lett., 14, 933-936.

$\longrightarrow,-$, and P. Keckhut, 1991: Climatology of the middle at- mospheric temperature ( $30-90 \mathrm{~km}$ ) and trends as seen by Rayleigh lidar above South of France. J. Geophys. Res., 96, 15 29715309 .

,-- P. Keckhut, and D. Nedeljkovic, 1992: Lidar monitoring of the temperature in the middle and lower atmosphere. Appl. Phys., B55, 29-34.

Jenkins, D. B., D. P. Wareing, L. Thomas, and G. Vaughan, 1987: Upper stratospheric and mesospheric temperature derived from lidar observation at Aberystwyth. J. Atmos. Terr. Phys., A9, 287-298.

Keckhut; P., and M. L. Chanin, 1989: Seasonal variation of the 11 year solar effect on the middle atmosphere; Role of the QBO. Map Handbook, 29, 33-38.

- , and - 1992: Middle atmosphere response to the 27-day solar rotation as observed by lidar. Geophys. Res. Lett., 19, 809812 .

,-- , and A. Hauchecorne, 1990: Stratospheric temperature measurement using Raman lidar. Appl. Opt., 29, 5182-5186.

Kent, G. S., and R. W. Wright, 1970: Review of laser radar measurements of atmospheric properties. J. Atmos. Terr. Phys., 32, 917-943.

Lefrère, J., J. Pelon, C. Cahen, A. Hauchecorne, and P. Flamant, 1981: Lidar survey of the post Mt. St. Helens stratospheric aerosol at Haute-Provence Observatory. Appl. Opt., 20, 1117.

Lubken, F. J., W. Hilert, G. Lehmacher, U. Von Zahn, M. Bittner, D. Offermann, F. J. Schmidlin, A. Hauchecorne, M. Mourier, and P. Czechowsky, 1992: Intercomparison of density and temperature profiles obtained by lidar, ionization gauges, falling spheres, datasondes and radiosondes during DYANA campaign. J. Atmos. Terr. Phys., submitted.

Mac Cormick, P. D., E. C. Silverberg, S. K. Poultney, U. Van Vijk, C. O. Alley, and R. T. Bettinger, 1967: Optical radar detection of backscattering from the upper atmosphere. Nature, 215, 12621263.

Nash, J., and F. J. Schmidlin, 1987: Final report of the WMO International Radiosonde Intercomparison. Report 30, WMO, 120 pp.

Remsberg, E. E., 1986: The accuracy of Nimbus 7 LIMS temperature in the mesosphere. Geophys. Res. Lett., 13, 311-314.

Russell, P. B., T. J. Swissler, and U. Van Zahn, 1989: First detection of noctilucent cloud by lidar. Geophys. Res. Lett., 16, 14451448.

Sandford, M. C. W., 1967: Laser scatter measurements in the mesosphere and above. J. Almos. Terr. Phys., 29, 1657-1658.

Schmidlin, F. J., 1981: Repeatability and measurement uncertainty of the United States meteorological rocketsonde. J. Geophys. Res., 86, 9599-9603.

- M. S. Lee, and W. Michel, 1991: The inflatable sphere: A technique for the accurate measurement of middle atmosphere temperatures. J. Geophys. Res., 96, 22 673-22 682.

Thomas, G. E., 1984: Solar Mesosphere Explorer measurements of polar mesospheric clouds. J. Atmos. Terr. Phys., 46, 819-824.

Wilson, R., M. L. Chanin, and A. Hauchecorne, 1990: Gravity waves spectra in the middle atmosphere as observed by Rayleigh lidar. Geophys. Res. Letl., 7, 1585-1588.

$-\ldots$, and -1991 a: Gravity waves in the middle atmosphere by Rayleigh lidar, Part 1: Case studies. J. Geophys. Res., 96, 5153-5167.

$\ldots,-\frac{1}{2}$, and $-1992 \mathrm{~b}$ : Gravity waves in the middle atmosphere by Rayleigh lidar, Part 2: Climatology. J. Geophys. Res., 96, 5169-5183. 